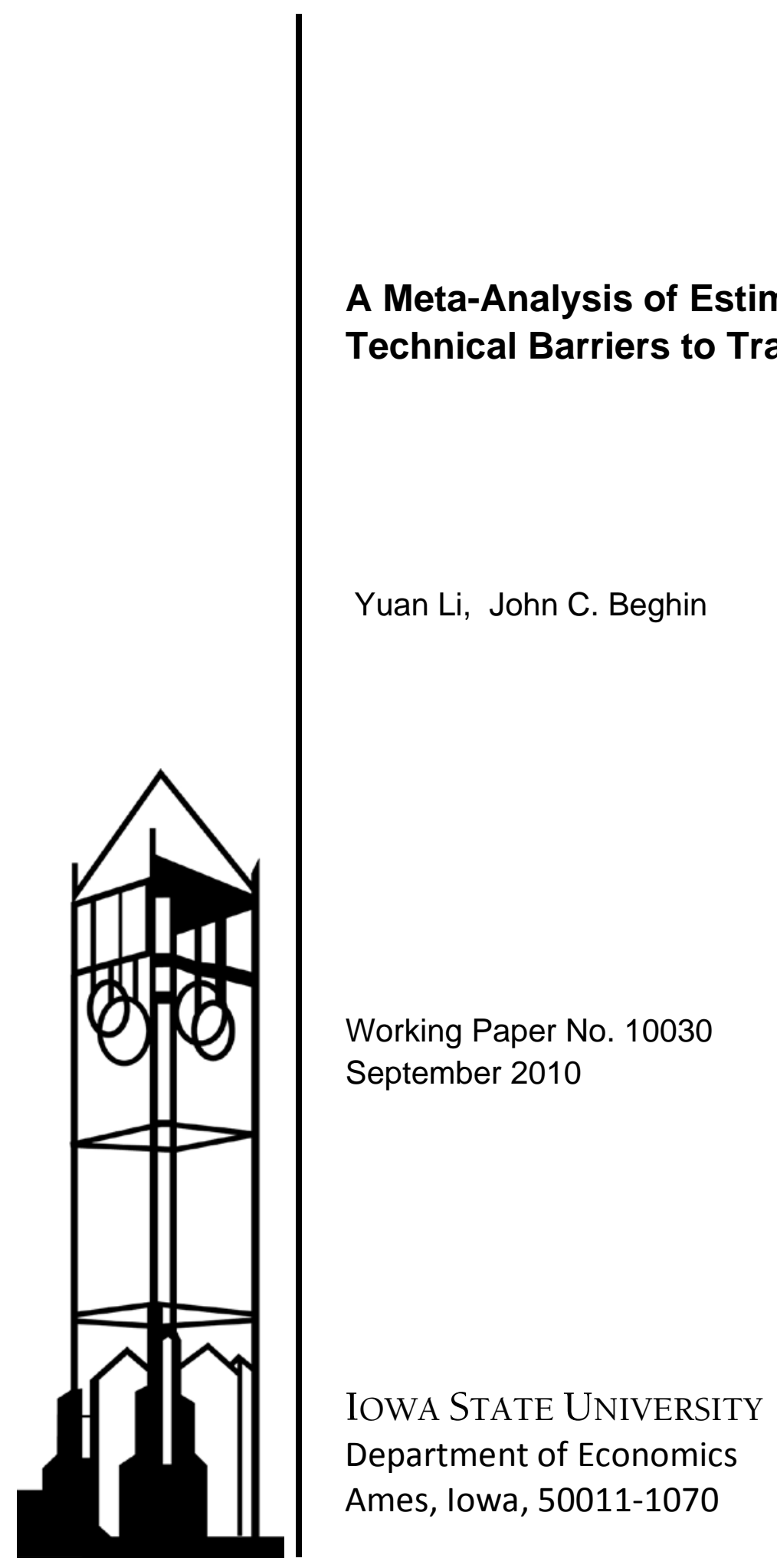

lowa State University does not discriminate on the basis of race, color, age, religion, national origin, sexual orientation, gender identity, sex, marital status, disability, or status as a U.S. veteran. Inquiries can be directed to the Director of Equal Opportunity and Diversity, 3680 Beardshear Hall, (515) 294-7612. 


\title{
A Meta-Analysis of Estimates of the Impact of Technical Barriers to Trade
}

\author{
Yuan Li \\ John C. Beghin* \\ Iowa State University
}

This draft: November 19, 2010

\begin{abstract}
A meta-analysis explains the variation in estimated trade effects of technical barriers to trade broadly defined, using available estimates from the empirical international trade literature, and accounting for data sampling and methodology differences. Agriculture and food industries tend to be more impeded by these barriers than other sectors. SPS regulations on agricultural trade flows from developing exporters to high-income importers tend to impede trade. Controlling for "multilateral resistance" lowers the propensity to find that these policies impede trade. Estimations correcting endogeneity by using panel data and time fixed effect yield more negative (or less positive) trade effects of technical measures.
\end{abstract}

Keywords: TBT, SPS, technical measures, technical barriers to trade, phytosanitary regulation, trade effect, meta-analysis, non-tariff measure

JEL Code: F13, F14, Q17, Q18

*Yuan Li is a PhD Candidate in the Economics Department at Iowa State University. John Beghin is Marlin Cole Professor of International Agricultural Economics in the same department. We thank Anne-Celia Disdier, Dermot Hayes, David Hennessy, Ivan Kandilov, Stephan Marette, John Schroeter, and Frank van Tongeren and workshop participants at North Carolina State University for comments on earlier drafts and discussions; we also thank Lionel Fontagné, Michele Nardella, and other authors who made their detailed estimation results available, and the OECD Trade and Agricultural Directorate for financial support. The views expressed here should not be attributed to the OECD. Contact author: John Beghin: 260 Heady Hall. Economics. Iowa State University Ames IA 50011-1030. USA. Email: beghin@iastate.edu. Phone: 1515294 5811.Fax: 15152940221. 


\section{Introduction}

Since tariffs have been decreasing, more attention has been paid to non-tariff barriers (NTBs), or as more recently called, non-tariff measures (NTMs). Due to their intrinsic heterogeneity, NTBs/NTMs are categorized into several relatively more homogeneous subgroups (Harrigan (1993); Deardorff and Stern (1998); Haveman, Nair-Reichert, and Thursby (2003); and Fontagné, Mayer, and Zignago (2005)). Health and safety measures and technical standards, comprising Sanitary and Phyto-Sanitary Measures (SPS), Technical Barriers to Trade (TBTs), and other standard-like policies are often distinguished from other NTMs and their controversial effects on trade have been extensively analyzed. Ganslandt and Markusen (2001) explain how standards and technical regulations have both the trade-impeding effects by raising the costs of exporters and similar demand-enhancing effects by certifying quality and safety to consumers.

Our paper focuses on these TBTs SPS and standard-like policies, which we label technical measures ${ }^{1}$, and which affect international trade through changing production costs and/or enhancing demand. Empirical knowledge on technical measures has proliferated rapidly since the early 1990s, especially with investigations based on gravity equations. The literature shows a wide range of estimated effects from significantly impeding trade to significantly promoting trade. These results are difficult to rationalize without further formal investigation which we tackle in this paper with a meta-analysis. For example, Otsuki et al. (2001a, 2001b), Wilson and Otsuki (2001), and Wilson et al. (2003) found that stricter Maximum Residue Levels (MRLs) on aflatoxin or drug residues impeded trade. Chevassus-Lozza et al. (2008) found positive trade effects of sanitary measures, and negative or insignificant impacts of phytosanitary and quality measures. Disdier et al. (2008b) showed negative or insignificant impacts of TBTs and SPS on agricultural and food aggregate trade. They also investigated 30 disaggregated

\footnotetext{
${ }^{1}$ Technical measures include TBTs, SPS and standard-like policies covered by MAST categories A through C.
} 
industries at the HS2 aggregation level, and found that TBTs and SPS had positive effects for 8 industries, insignificant effects for 12 industries, and negative effects for 10 industries.

Disaggregated findings of Nardella and Boccaletti (2004), Fontagné et al. (2005), and others also reveal that the direction and the significance of the technical measures trade effects could vary significantly across product groups and trading partners. In sum, this rich evidence of both tradeimpeding and trade-enhancing effects of technical measures muddles their patterns, and creates a need for further rationalization.

The variations in findings are partly due to variations in their data samples, mostly variations in industry, country, and aggregation level, among other things. For example, Disdier et al. (2008b) found different TBTs and SPS trade effects for different exporters, and different industries. Beside the differences in data, variations in the trade effects may be caused by different forms of technical measures proxies, model specifications, and other methodology variations. Otsuki et al. (2001a, 2001b), Wilson and Otsuki (2001), and Wilson et al. (2003), use MRLs to proxy the strength of technical measures. MRLs enter the regression as numerical values, a straightforward and accurate measure of the technical measures of interest. However, in most cases, technical measures do not have direct numerical measurements, so proxies have to be constructed. Commonly used proxies of technical measures are dummy variables, ad valorem equivalent (ave) of the policies, frequency ratio, and count variables. Choices among these different proxies may lead to different estimates of trade effects of technical measures. Few researchers have tried and compared different proxies within their investigations (see Disdier et al. (2008b)), and most researchers only chose one.

Since the first foundation for gravity equations by Anderson (1979), advances in the specification of gravity equations have brought many variations and refinements. Empirical 
studies follow different theoretical underpinnings to different extents, which could also lead to variations in the estimated impact of technical measures on trade.

Deardorff and Stern (1998), Bureau and Beghin (2001), Maskus et al. (2001) distill the earlier literature on technical measures and associated methodologies to measure these policies and their effects. The earlier prevailing methods are still dominant today but with substantial advances. The refined theory underlying gravity equations (Feenstra (2004)) and econometric estimation techniques address new issues, such as the treatment of zero trade flows. In addition, in recent years, researchers tend to analyze technical-measure effects with disaggregated data and wider country and industry coverage.

Our meta-analysis attempts to statistically explain the variations in estimated trade effects of technical measures, taking both data sampling and methodology differences into consideration. Meta-analysis provides a more objective and systematic assessment of the empirical results than narrative reviews do. It uses statistical methods to investigate underlying patterns, which might otherwise look complex, and help us understand the core determinants to the variations in available estimates of the impact of technical measures.

\section{Specifications of the Gravity Equation}

In its simplest and early formulation, the gravity equation says that trade volume between two countries is directly proportional to the product of the countries GDPs and the distance between these two countries. It takes the usual reduced form:

$\log X_{i j}=\alpha_{0}+\alpha_{1} \log \left(Y_{i}\right)+\alpha_{2} \log \left(Y_{j}\right)+\alpha_{3} H_{i j}+\varepsilon_{i j}$,

where $X_{i j}$ is the value of trade from country $i$ to country $j . Y_{i}$ and $Y_{j}$ are the Gross Domestic Product (GDP) of country $i$ and country $j$. GDP is a proxy for production capacity in the 
exporting country, which at a sectoral level would be the supply of the exporter for that sector. GDP in the importing country is motivated by demand considerations of a representative consumer. Variable $H_{i j}$ includes variables that authors choose to explain the bilateral trade flow, such as distance between trade partners. The choice of the variables to be included is context specific and depends on the problem of interest. Variable $\varepsilon$ is the error term.

Many empirical applications of gravity equations are atheoretical. Researchers use equation (1) directly without specifying explicit underlying micro-foundations. This simple approach successfully explains trade flows but leaves the reader wanting for more conceptualization. Theoretical foundations eventually were spelled out. The gravity equation can be derived from a perfect competition model, monopolistic competition model, increasing return theories, or the Heckscher-Ohlin model, among others. Most derivations assume perfect specialization (Helpman (1987); Anderson (1979); and Anderson and van Wincoop (2003 and 2004)). Each country produces its unique variety of goods and exports this unique variety to all other countries. This assumption greatly simplifies the price structure, as shown below (see Evenett and Keller (2002) for an attempt to relax the perfect specialization assumption).

Accounting for trade costs makes derivations and estimations of gravity equation more difficult, because of the different price effects induced by trade costs. To see this, we derive the gravity equation with trade costs, following mostly the notation of Feenstra (2004). Beside the assumption of perfect specialization across countries, we further assume each country only specializes in one unique good for simplicity. In a free trade world without transaction cost, each good has a unique price, which is the same across countries, so we could normalize all prices to one and greatly simplify the problem. However, in real world applications, we need to consider trade costs and the variation of prices over time; normalization only works for one year. Trade 
costs generally include transportation costs, tariffs, costs related to NTBs, and other trade costs.

Suppose $p_{i j}$ is the price in country $j$ of the product produced in country $i$, and $p_{i}$ is the ex-factory price of the product produced in country $i$ before exports take place, that is, net of any trade costs. The aggregate trade cost factor associated with selling the product produced in country $i$ in country $j$ is denoted as $T_{i j}$. Hence, we have $p_{i j}=T_{i j} p_{i}$.

With CES preferences, the representative consumer maximizes $U_{j}=\sum_{i=1}^{C}\left(c_{i j}\right)^{(\sigma-1) / \sigma}$ subject to $Y_{j}=\sum_{i=1}^{C} p_{i j} c_{i j}$, where $U_{j}$ is the utility for country $j$; number $C$ is the total number of countries. Variable $c_{i j}$ is the consumption in country $j$ of the good produced in country $i$. Multiplying $c_{i j}$ by price $p_{i j}$ provides the total value of country $i$ 's exports to country $j$, denoted as $X_{i j}=p_{i j} c_{i j}$. Aggregate income or GDP of country $j, Y_{j}$ is equal to the production value $Y_{j}=p_{j} y_{j}$, where $y_{j}$ is the output production in country $j$. Corresponding demand functions are $c_{i j}=\left(p_{i j} / P_{j}\right)^{-\sigma}\left(Y_{j} / P_{j}\right)$, with $P_{j}=\left(\sum_{i=1}^{C}\left(p_{i j}\right)^{(1-\sigma)}\right)^{1 /(1-\sigma)}$ the overall price index in country $j$. Combining the latter with $X_{i j}=p_{i j} c_{i j}$, we have $X_{i j}=Y_{j}\left(\frac{p_{i j}}{P_{j}}\right)^{1-\sigma}$. We then substitute $p_{i j}=T_{i j} p_{i}$ into the latter to obtain a gravity-like function $X_{i j}=Y_{j}\left(\frac{p_{i} T_{i j}}{P_{j}}\right)^{1-\sigma}$

Total production (or GDP) of country $i$ does not appear in (2) as in (1). To further link (2) to the gravity equation, we slightly deviate from Feenstra (2004), which follows the symmetric trade costs assumption $\left(T_{i j}=T_{j i}\right)$ of Anderson and von Wincoop (2003). We derive a more 
general gravity expression, and then compare the implications of different restrictive assumptions or estimation methods such as normalization of prices and symmetric trade costs. The market-equilibrium condition $y_{i}=\sum_{j=1}^{C} c_{i j} T_{i j}$ says that production of good $i$ is equal to the sum of its demands over all destinations and inclusive of the resource cost associated with trade costs (expressed in units of good $i$ ). It implies that $Y_{i}=p_{i} y_{i}=p_{i} \sum_{j=1}^{C} c_{i j} T_{i j}$. Then we make use of $p_{i j}=T_{i j} p_{i}$ to obtain $Y_{i}=\sum_{j=1}^{C} c_{i j} p_{i j}$. Substitute $c_{i j}=\left(p_{i j} / P_{j}\right)^{-\sigma}\left(Y_{j} / P_{j}\right)$ to get $Y_{i}=\sum_{j=1}^{C}\left(p_{i} T_{i j} / P_{j}\right)^{1-\sigma} Y_{j}$

Define the world GDP $Y_{W}=\sum_{j=1}^{C} Y_{j}$, and country $i$ 's share of world GDP $\theta_{i}=Y_{i} / Y_{W}$. Divide both sides of (3) by $Y_{W}$ and define $\tilde{P}_{i}=\left(\sum_{j=1}^{c}\left(p_{i} T_{i j} / P_{j}\right)^{1-\sigma} \theta_{j}\right)^{1 /(1-\sigma)}$ to obtain

$$
\left(\tilde{P}_{i}\right)^{\sigma-1} \frac{Y_{i}}{Y_{w}}=1
$$

Apply (3') to (2) to get

$$
X_{i j}=\frac{Y_{i} Y_{j}}{Y_{w}}\left(\frac{T_{i j}}{P_{j} \tilde{\tilde{P}}_{i}}\right)^{1-\sigma},
$$

with $\tilde{\tilde{P}}_{i}=\tilde{P}_{i} / p_{i}$. In equation (4), variables $P_{j}$ and $\tilde{\tilde{P}}_{i}$ are called "multilateral resistance" terms. More specifically, $P_{j}$ is an importer-specific function of overall distortions of prices on all exporters imposed by importer $j$ through trade costs. $\tilde{\tilde{P}}_{i}$ is an exporter-specific function of overall distortions faced by exporter $i$ in all destination markets.

Taking the log of (4) provides a generalized expression of the traditional gravity equation 
(1) under asymmetric cost, which explains the presence of $P_{j}$ and $\tilde{\tilde{P}}_{i}$. Both indices depend on trade costs and price indexes of all the trading partners. This specification poses a problem for the empirical estimation, since it is hardly possible to take all trading partners into account. Anderson and von Wincoop (2003) assume symmetric trade costs, and get an implicit solution to the "multilateral resistance" term, which is similar to equating $P_{j}$ and $\tilde{\tilde{P}}_{i}$ or to assuming exfactory prices $p_{i}$ normalized to one. The symmetric trade costs assumption is unrealistic in most cases. To overcome this undesirable assumption, Harrigan (1996), Hummels (1999), Redding and Venables (2004), and Rose and van Wincoop (2001) introduced country fixed effects to account for $P_{j}$ and $\tilde{\tilde{P}}_{i}$. Feenstra (2004) tested the fixed effect method and Anderson and von Wincoop (2003) method, and found they did almost equally well.

To implement the derived gravity equation, one needs to choose a functional form for the trade costs. Authors usually choose multiplicative forms, such as $T_{i j}=\prod_{q=1}^{Q}\left(T C_{i j}^{q}\right)^{\gamma^{q}}$, for simplicity, and variables TC often come from previous empirical findings and/or certain estimated trade costs the author is interested in. In practice, Variables TC typically include distances, tariffs, non-tariff barriers such as TBTs and SPS measures, and others. The estimated responses $\gamma^{q}(1-\sigma)$ are the coefficient of interest for our meta-analysis when they pertain to technical measures.

In our meta-analysis of the estimates of technical-measure trade effects, we explain the variations of these estimates by two classes of explanatory variables. One class captures the variations in the model specification and estimation techniques, and the other class captures the subpopulation variations. We elaborate on these two points next. 


\section{Meta Analysis}

We construct explanatory variables based on theoretical arguments as well as conjectures expressed in the literature regarding important matters explaining these estimated impacts. The objective is to control for the determinants that are most likely to matter. The limitation of the data also restricts the determinants we can investigate as collinearity arises from the multiplicity of categorical variables.

\subsection{Variations in estimation methods}

First, we look at classic errors in gravity estimations. Baldwin and Taglioni (2006) pointed out three mistakes in gravity equations that could lead to biasness in gravity equation estimates: the "gold medal error", "silver medal error," and "bronze medal error." The "gold medal error" refers to the failure to include the relative price terms, which are equivalent to $P_{j}$ and $\tilde{\tilde{P}}_{i}$ in (4), derived above. The omission of $P_{j}$ and $\tilde{\tilde{P}}_{i}$ causes the omitted trade cost variables in the error term to be correlated with the trade cost variables accounted for. As discussed in the gravity equation section, the "multilateral resistance term" or fixed effects approximating the term could correct this mistake.

The "silver medal error" refers to the situation when researchers mistakenly use the logarithm of the average instead of the average of the logarithm of trade flows (average of exports and imports). The "bronze medal error" is caused by inappropriately deflating trade values using the same deflator, say the U.S. consumer price index, and the resulting "spurious" correlation from the common deflator causes biases. This error would be a problem for multiyear data; time-series dummies could correct the biasness. In the meta-analysis, we use dummy variables to control for the presence or not of correction for "gold" and "bronze" errors, or more specifically, the inclusion of country fixed effects and/or time fixed effects used to estimate the 
technical measure effects. However, as "silver errors" are extremely scarce in our sample of studies, we are not able to consider this category in our analysis.

Second, we consider the treatment of zero-trade flows in the collected investigations. Since the gravity equation takes a log-linear form, the zero trade observations pose a problem for the estimation and raise the issue of sample selection bias, among others. A commonly used technique is to drop the zero trade observations. But if zero trade is due to the missing values, rounding, or no trade, then dropping those observations could lead to bias. Several techniques exist to retain the zeros. A simple practice to deal with the zero-trade problem is to add a small arbitrary number to all trade values, and make the log of zero trade a negative value. This method is quite arbitrary and could lead to some bias although the direction of the bias is not clear. There are some important advances in this issue in recent years. Silva and Tenreyro (2006) suggested a Poisson pseudo-maximum-likelihood (PPML) technique to estimate the gravity equation in its multiplicative form and in levels instead of the commonly used log linear form. This technique naturally solves the numerical problem of zero trade and is also robust to heteroskedasticity in errors. However, it could also be biased as predicted trade is positive with the exponential functional form.

However, Martin and Pham (2008) show that the PPML method could also be seriously biased if zero trades are frequent. The zero-inflated Poisson (ZIP) model (Lambert, 1992) improves upon the PPML and is able to handle excess zeros. More specifically, the probability of having zero trade is estimated with a logit/probit, and the non-zero trade part is estimated with PPML. The Tobit model and the Heckman two-step model are other methods used to address zero trade observations. The choice between these two methods is mostly based on authors' beliefs in the causes of zero trade observations. If zero trade is allegedly caused by censored 
data, then it is appropriate to use Tobit model. On the other hand, if zero trade is suspected to be caused by decisions or self-selection, they may choose the Heckman two-stage procedure instead. Helpman, Melitz and Rubinstein (2008) (HMR hereafter) developed a novel modified two-stage estimation technique by accounting for firm heterogeneity and the extensive margin from new firms entering into export markets. Their approach enables the investigation of both intensive margin (existing trade) and extensive margin from new firms entering trade, hence differentiation between fixed and variable trade costs.

However, due to the different popularity of procedures and limited availability of the studies, especially the relative scarcity of the studies based on PPML, ZIP, Tobit, Heckman twostage model or HMR, we can only attempt to distinguish the difference between groups of these econometric procedures (see Appendix A for the frequency table of different procedures). We tried three groupings based on our conjectures of their commonality. First, we controlled truncation (dropping zero data) versus other procedures. Second, we grouped modeling procedures that address zero data explicitly (ZIP, Tobit, Heckman two-stage, HMR) versus numerical accommodation of zero data (truncation, PPML, and adding small numbers). Third, we grouped PPML and adding small numbers based on the conjecture that they may cause bias from forcing level equation to accommodate zero data as small positive predicted or actual values. However, the dominant number of estimates from studies relying on truncation leads to similar meta-analysis estimation results ${ }^{2}$ between the first and second grouping (excluding or including PPML and adding small number procedure). Further, the third grouping is too skewed for MNL regression. To avoid ambiguity, we choose the first grouping and use a dummy variable, which equals zero if truncation is applied and equals one if zero data are treated with other procedures.

2 Estimation results for the second grouping are available upon request. 
Third, endogeneity of the barriers to trade is another problem that might cause bias, since it is reasonable to argue that trade expands first and regulations, like TBTs, may come after as protectionism. Trefler (1993), and Lee and Swagel (1997) showed that the endogeneity problem could lead to the underestimation of NTMs' impact on trade. Unfortunately, few studies in our sample addressed this problem directly. Baier and Bergstrand (2007) pointed out that a panel data approach could handle the endogeneity problem very well with panel data and fixed time effects. So we account when a paper uses panel data with time fixed effects as a way to address endogeneity.

Fourth, the choice of technical measure proxy used in the investigations provides methodology variation which translates into a variation in data characteristics. Technical measure studies may differ in their choices of policy proxy measures: dummy variables for the existence of measures, count variable, frequency index, and ad-valorem equivalent (AVE) are commonly used. The literature has not settled yet on the best way to measure technical measures and which proxy measure is the best if any. For example, the AVE estimated by Kee et al. (2006) had some potential problems in its estimation procedures as it constrains NTMs effects to be trade restrictive and rules out trade expansion effects. Intuitively, the proxy choice could affect the variation in the estimates. Finally, quite of few studies based on panel data with time dimension, ignore the time variation in the TBT proxy. This omission may have some systematic impact on the trade effects, so we use a dummy to control whether the proxy exhibits time variation, provided that panel data was used.

\subsection{Subpopulation characteristics}

Data subpopulations used to estimate the effects of technical measures on trade differ by trading partners, industry coverage, and aggregation level. Trading-partner variations can be controlled 
by the development status of exporters/importers. Further, trade effects could be significantly different across agricultural (sectors HS01-HS15 in the Harmonized System 2-digit level), processed food and beverage (HS16-HS25), and manufacturing products (HS26-HS99). In addition, in the context of North-South trade, we are interested to test the hypothesis that SPS regulations inhibit trade of agricultural products between developing exporters and developed importers rather than being catalyst of trade. This is an unsettled debate in the literature.

Further, the sectoral aggregation level of the trade flow used in the investigations also matters for the size and variation of the trade effects (Hillberry (2002)). We use the digit of the Harmonized System (HS) indicating the aggregation level as the measure of aggregation level of the data. 2-digit HS, 4-digit HS, or 6-digit HS, measure the aggregation level takes values of 2, 4, and 6, respectively. The HS aggregation digit is an ordinal number, but for regression purpose, we use it as cardinal number to measure the disaggregation level with the usual limitations of doing so. The motivation is to limit the multiplicity of dummy variables compounding singularity issues in our investigation.

\section{Our Dataset of SPS/TBT Studies}

Our data set includes 27 papers that use gravity equations to estimate technical-measure effects on trade flows, and totals 618 observations. Table 1 lists the studies and the number of estimates collected from each study and the sector coverage. The selection of our studied sample is based on availability. We have performed extensive searches with Econlit, REPEC, SSRN, IATRC, Agecon Search, and other web-servers and working paper repositories completed by summer 2009.

The first criterion used to select investigations is that the study investigates the trade 
effects of technical measures. We focus on technical measures, rather than on all NTMs because "all NTMs" include all barriers but tariffs, and lack communality of effects on agents' decisions. For example, many classifications of NTMs include macro policies, price control measures, quantity control measures, etc. (Deardorff and Stern (1998)). Too wide of a policy coverage would dilute the validity and precision of the meta-analysis, but too narrow of a coverage could lack generality on how technical measures are believed to affect international trade through changing production costs and/or enhancing demand through quality and information effects. 
Table 1: The list of papers included and the number of estimates per paper

\begin{tabular}{clcl}
\hline $\begin{array}{c}\text { Paper } \\
\text { Index }\end{array}$ & $\begin{array}{c}\text { Author(s) } \\
\text { Estimates }\end{array}$ & Industry Coverage \\
1 & Disdier, Fontagné, Mimouni (2008) & 38 & $\mathrm{Ag}$, Food, Manufacturing \\
2 & Wilson and Otsuki (2004) & 2 & $\mathrm{Ag}$ \\
3 & Disdier and Marette (2009) & 2 & $\mathrm{Ag}$ \\
4 & Olper and Raimondi (2008) & 1 & $\mathrm{Food}$ \\
5 & Chevassus-Lozza et al. (2008) & 6 & $\mathrm{Ag}$, Food \\
6 & Nardella and Boccaletti (2004) & 40 & $\mathrm{Ag}$, Food \\
7 & Wilson, Otsuki, and Majumdar (2003) & 2 & $\mathrm{Ag}$ \\
8 & Disdier, Fekadu, Murillo, and Wong (2008) & 84 & $\mathrm{Ag}$, Food \\
9 & Otsuki, Wilson, and Sewadeh (2001a) & 2 & $\mathrm{Ag}$, Food \\
10 & Otsuki, Wilson, and Sewadeh (2001b) & 3 & $\mathrm{Ag}$ \\
11 & Wilson and Otsuki (2001) & 3 & $\mathrm{Ag}$ \\
12 & Disdier and Fontagné (2008) & 46 & $\mathrm{Ag}$ \\
13 & Chen, Yang, and Findlay (2008) & 5 & $\mathrm{Ag}$ \\
14 & Babool and Reed (2007) & 1 & $\mathrm{Ag}$, Food \\
$15 *$ & Gebrehiwet, Naqangweni and Kirsten(2007) & 2 & $\mathrm{Food}$ \\
16 & Anders and Caswell(2006) & 9 & $\mathrm{Ag}$ \\
17 & Nguyen and Wilson (2009) & 21 & $\mathrm{Ag}$ \\
18 & Jayasinghe, Beghin, and Moschini (2009) & 6 & $\mathrm{Ag}$ \\
$19 *$ & Scheepers, Jooste, Alemu (2007) & 1 & $\mathrm{Ag}$ \\
20 & Nardella and Boccaletti (2003) & 8 & $\mathrm{Ag}$, Food \\
21 & Nardella and Boccaletti (2003) & 90 & $\mathrm{Ag}$, Food \\
22 & Fontagné, Mimouni, and Pasteels (2005) & 182 & $\mathrm{Ag}$, Food, Manufacturing \\
23 & Chen, N (2004) & 2 & Food, Manufacturing \\
24 & Fontagné, Mayer, and Zignago (2005) & 1 & Food, Manufacturing \\
25 & Blind and Jungmittag (2005) & 4 & $\mathrm{Ag}$, Food, Manufacturing \\
26 & Blind(2001) & 4 & $\mathrm{Manufacturing}$ \\
27 & Harrigan (1993) & 56 & Food, Manufacturing \\
Total & & $\mathbf{6 1 8}$ & \\
\hline
\end{tabular}

* Estimates are dropped because of missing sample size information

The second criterion of our selection is that the empirical model used in the study has to be based on the gravity equation. Using the derived gravity equation (4) and including an explicit technical measure trade cost proxy variable, and then taking logarithm of both sides lead to:

$\log X_{i j}=\alpha_{0}+\alpha_{i}+\alpha_{j}+\alpha_{1} \log \left(Y_{i}\right)+\alpha_{2} \log \left(Y_{j}\right)+\gamma^{1}(1-\sigma) T M_{i j}+\gamma^{2}(1-\sigma) H_{i j}+\varepsilon_{i j}$, 
where $\alpha_{i}$ and $\alpha_{j}$ correspond to the "multilateral resistance" terms $P_{i}$ and $\tilde{\tilde{P}}_{i}$. The coefficients of the $\log$ of GDPs are not always restricted to 1 in practice. The coefficient $\gamma^{1}(1-\sigma)$ represents the impact of technical measures on trade flows $\partial\left(\log X_{i j} \mid Y_{i}, Y_{j}, T M_{i j}, H_{i j}\right) / \partial T M_{i j}$. Given $X_{i j}$ and $T M_{i j}$, the value of $\gamma^{1}(1-\sigma)$ depends on the log linear form of $X_{i j}$ as well as all the information upon which it is conditioned. We use explanatory variables which capture the variations in information from one study to the next. Hence, estimates from the same gravity model are comparable in a conceptual sense.

In addition, papers in our sample differ from the ones that analyze the trade effects of harmonized or reciprocal technical measures as opposed to idiosyncratic measures (Moenius (2004, 2007a, 2007b); Blind (2001); Blind and Jungmittag (2005); and Swann et al. (1996)). The latter investigations of technical measures intend to gauge the impact of the harmonized technical measures as opposed to unilateral national measures. Papers in our sample studied the general technical measure impacts abstracting away from this complication of the potential impact of harmonized or reciprocal policies.

\section{Meta-Analysis}

Pooling the technical measure trade effects in a meta-analysis, we compare the trade effects of different polices or different proxies. Many policies are categorized as technical measures. Nardella and Boccaletti (2005), and Anders and Caswell (2006) estimated the impact of hazard analysis and critical control points on trade. Otsuki et al. (2001a, 2001b) investigated the trade effects of aflatoxin residue standards. In addition, researchers could use different technical measure proxy types (count of measures, dummies, AVEs, among others). One cannot represent these effects under a common metric such as elasticity as was done for distance elasticities in 
Disdier and Head (2005). This heterogeneity of representations of TBTs creates a conundrum which we resolve as follows.

The estimates of different technical measure proxies have different scales and some are continuous, whereas others are dichotomous. One could think of categorical variables, classifying the available estimates into three sets (negative significant, insignificant, and positive significant, respectively). The latter classification corresponds to the barrier/catalyst view of TBT policies. In addition, one would like to preserve further information, like magnitude of estimates and significance levels which would be lost by just using categorical variables to pigeonhole the estimates. To achieve this, we use the t-values of the available technical measure estimates. The t-value, defined as the point estimate divided its standard error, is unit free, so we make the estimates comparable. By using t-values, we sacrifice the information on the magnitude of the effect but we keep the direction of the effect and the magnitude of the significance of the estimates. A positive coefficient on the right-hand side covariates in the meta-analysis means the explanatory variable has a trade enhancing effect (or less trade-impeding effect), and vice versa.

The basic meta analysis model is: $t^{e s}=\beta_{0}+\sum_{k=1}^{K} \beta_{k} Z^{k e s}+\mu^{e s}$,

where $t^{e s}$ is the t-value of the $e$-th estimate of the $s$-th study, $Z^{\text {kes }}$ is the $k$-th explanatory variable used to capture the variation in characteristics of the studies. Note that we use multiple estimates from one study so as to keep as much variation and information as possible.

Although we control for some important characteristics as stated above, there are more intrinsic differences among studies left in the error terms $\mu^{e s}$. Thus, violations of normality, heteroskedasticity, outliers, and influential data points are likely to exist in our sample of studies. Therefore, we adopt a robust regression technique to deal with the unknown underlying distributions in addition to regular least squares. As we use multiple estimates from one study, 
the estimates from the same study are likely to be correlated. Robust regression could also downweight clusters, to prevent the study that provides more estimates from having unduly influence. We detect and down-weight outliers and influential data points by examining residuals and some influence statistics (i.e. Cook's distances, DIFIT, etc). We do not delete them, however, to preserve data. Robust regression mitigates the problem of outliers and influential data points by down-weighting them, and makes the estimates more resistant to their influence (Belsley et al. (1980)).

In addition to the linear OLS and robust regression models, we employ a multinomial logit (MNL) model to help interpretation of results and we check their consistency with the robust regression results. In the MNL approach we split the data into significantly negative estimates ( $\mathrm{t}$ value smaller than -1.96), insignificant ones ( $\mathrm{t}$ value comprised within $(-1.96,1.96))$, and positively significant ones (t-value larger than 1.96). The approach is

$$
\begin{aligned}
& \log \left(\frac{\operatorname{Pr}(D=1)}{\operatorname{Pr}(D=2)}\right)=\beta_{10}+\sum_{k=1}^{K} \beta_{1 k} Z^{\text {kes }}+\mu^{\text {les }}, \\
& \log \left(\frac{\operatorname{Pr}(D=3)}{\operatorname{Pr}(D=2)}\right)=\beta_{20}+\sum_{k=1}^{K} \beta_{2 k} Z^{\text {kes }}+\mu^{2 e s},
\end{aligned}
$$

where $D$ is a categorical variable equal to 1 if the corresponding $t_{\mathrm{ij}} \leq-1.96$, equal to 2 if $-1.96<$ $t_{\mathrm{ij}}<1.96$, and equal to 3 if $t_{\mathrm{ij}} \geq 1.96$. Each paper can be seen as a cluster, and we have multiple observations from each cluster and independent clusters. We use a robust estimator of the clustered error structure, assuming independence among clusters, but dependence among observations that are within the same cluster. The estimates from the MNL regression show the impact of the explanatory variables on log odds, not the impact on the probability of the categorical variable $D$. We normalize the probabilities $(\operatorname{Pr}(D=1)+\operatorname{Pr}(D=2)+\operatorname{Pr}(D=3)=1)$, to derive the conditional probabilities: 


$$
\begin{aligned}
& P_{1} \equiv \operatorname{Pr}\left(D=1 \mid Z^{1 e s}, Z^{2 e s}, \ldots, Z^{k e s}\right)=\frac{e^{\beta_{10}+\sum_{k=1}^{K} \beta_{1 k} Z^{\text {kes }}}}{1+e^{\beta_{10}+\sum_{k=1}^{K} \beta_{1 k} Z^{\text {kes }}}+e^{\beta_{20}+\sum_{k=1}^{K} \beta_{2 k} Z^{\text {kes }}}}, \\
& P_{2} \equiv \operatorname{Pr}\left(D=2 \mid Z^{\text {les }}, Z^{2 e s}, \ldots ., Z^{k e s}\right)=\frac{1}{1+e^{\beta_{10}+\sum_{k=1}^{K} \beta_{1 k} Z^{k e s}}+e^{\beta_{20}+\sum_{k=1}^{K} \beta_{2 k} Z^{k e s}}}, \text { and } \\
& P_{3} \equiv \operatorname{Pr}\left(D=3 \mid Z^{1 e s}, Z^{2 e s}, \ldots ., Z^{k e s}\right)=\frac{e^{\beta_{20}+\sum_{k=1}^{K} \beta_{2 k} Z^{k e s}}}{1+e^{\beta_{10}+\sum_{k=1}^{K} \beta_{1 k} Z^{k e s}}+e^{\beta_{20}+\sum_{k=1}^{K} \beta_{2 k} Z^{\text {kes }}}} .
\end{aligned}
$$

The associated marginal effects are:

$$
\begin{aligned}
& \frac{\partial P_{1}}{\partial Z^{k}}=P_{1}\left(\beta_{1 k} P_{2}+\left(\beta_{1 k}-\beta_{2 k}\right) P_{3}\right), \\
& \frac{\partial P_{2}}{\partial Z^{k}}=-P_{2}\left(\beta_{1 k} P_{1}+\beta_{2 k} P_{3}\right), \text { and } \\
& \frac{\partial P_{3}}{\partial Z^{k}}=P_{3}\left(\beta_{2 k} P_{2}+\left(\beta_{2 k}-\beta_{1 k}\right) P_{1}\right) .
\end{aligned}
$$

Conditional probabilities and marginal effects all depend on all Z's and $\beta$ 's, so we condition the interpretation on the latter evaluated at the mean of all Z's.

To summarize, the following variables are included in our meta-analysis specification: Fix_country_pair: a dummy variable, which equals 1 if panel data and the model has country-pair fixed effects; Panel_fix_time: a dummy variable, which equals 1 if panel data and the model with time fixed effects; Panel_var_time: a dummy variable, which equals 1 if panel data and proxy has time variation; Zero_treated: a dummy variable, which equals 1 if zero-trade is treated with two-stage, Tobit, PPML, etc.; $A g$ : a dummy variable, which equals 1 if the related products are agricultural products; Food: a dummy variable, which equals 1 if the related products are processed food, beverage; Мanu: a dummy variable, which equals 1 if the related products are manufacturing products; dev_SPS: a dummy variable, which equals 1 if data refer to and developing exporters, and developed importers, and agricultural products affected by SPS 
measures; Sample_centered: a number, the sample size of each study, centered at its mean 14,172.53, and scaled by 10,000; Agg_hs_centered: a number, the \# of HS digits of the data, centered by the aggregation level 5.14 (average of the variable); Proxy_dummy: a dummy variable, which equals 1 if the proxy of technical measures is a dummy variable; Proxy_count: a dummy variable, which equals 1 if the proxy of technical measures is a count variable; Proxy_freq: a dummy variable, which equals 1 if the proxy of technical measures is a frequency or coverage ratio variable; a Proxy_mrl: dummy variable, which equals 1 if a maximum residue level (MRL) is used directly, or equivalently, if the related policy is a MRL; SPS_no_mrl: a dummy variable, which equals 1 if the related policy is SPS but not measured by a MRL; and TBT: a dummy variable, which equals 1 if the related policy is a TBT.

Table 2 provides summary statistics on how the collected observations are pigeonholed according to their characteristics, and the statistical significance and sign of their TBT estimates. Dummy variables capture the sample or model specification choices, and they are intrinsically uncorrelated. Unlike experimental data with the number of "controlled" observations and “experimental" observations perfectly balanced, for our observational data, we cannot control the "balance" of the data. In the first two columns of table 2, we check the balance of the data by calculating the number of papers and estimates corresponding to each dummy variable applied in the meta-analysis. For example, 21 out of 28 papers estimated trade effects in agricultural sectors, 13 out of 28 papers estimated trade effects in the food sector, and only 7 in manufacturing.

Ideally, we would like the coverage to be more evenly distributed across sectoral activities. Similarly, the second column indicates the number of estimates for which a categorical variable is equal to 1 . For example, 392 out of 618 estimates are estimated from the gravity 
equations with country-pair fixed effects. Although we don't have perfectly balanced data, the first two columns show that the data is not very skewed or unbalanced. As we estimate MNL model, every variable must have some variations within each category $D=1,2,3$. From the last three columns of table 2, variables Proxy_mrl and Panel_fix_time have no variations when $D=3$, so we exclude these two variables in the MNL model.

Table 2: Summary statistics on the distribution of observations of categorical variables for D1 (negative significant), D2 (insignificant), and D3 (positive significant)

\begin{tabular}{lccccc}
\hline $\begin{array}{l}\text { Explanatory } \\
\text { Variable in meta } \\
\text { analysis }\end{array}$ & $\begin{array}{c}\text { Number of } \\
\text { papers affected } \\
\text { by exp. variable } \\
\text { (dummy=1) }\end{array}$ & $\begin{array}{c}\text { Number of } \\
\text { estimates } \\
\text { for which } \\
\text { dummy=1 }\end{array}$ & $\begin{array}{c}\text { Breakdown } \\
\text { for negative } \\
\text { effects } D=1\end{array}$ & $\begin{array}{c}\text { Breakdown } \\
\text { for insig. } \\
\text { effects } D=2\end{array}$ & $\begin{array}{c}\text { Breakdown } \\
\text { for positive } \\
\text { effects } D=3\end{array}$ \\
\hline Fix_country_pair & 13 & 392 & 101 & 242 & 49 \\
Panel_fix_time & 7 & 73 & 49 & 24 & 0 \\
Panel_var_time & 8 & 94 & 58 & 32 & 4 \\
Zero_treated & 9 & 291 & 88 & 158 & 45 \\
Ag & 21 & 347 & 144 & 159 & 45 \\
Food & 15 & 192 & 77 & 84 & 29 \\
Manu & 7 & 177 & 42 & 105 & 30 \\
dev_SPS & 8 & 143 & 61 & 74 & 8 \\
Proxy_dummy & 7 & 169 & 68 & 93 & 8 \\
Proxy_count & 6 & 152 & 57 & 55 & 40 \\
Proxy_freq & 5 & 241 & 53 & 155 & 33 \\
Proxy_mrl & 10 & 20 & 18 & 2 & 0 \\
SPS_no_mrl & 13 & 537 & 171 & 296 & 70 \\
TBT & 14 & 451 & 116 & 267 & 68 \\
\hline
\end{tabular}

\section{Estimation Steps and Results}

We check the data for some potential collinearity as we have numerous dichotomous variables. If collinearity is a problem, it can confound our estimation. We use the conditioning index, variance inflation index (VIF), and variance-decompositions jointly to diagnose the multicollinearity problems in our sample (Belsley et al. (1980)). Practically, multicollinearity may be a serious problem when the conditioning index is greater than 30 , the VIF is greater than 10 , and variance-decomposition proportions for two or more estimated regression coefficient variances 
are higher than 0.5 .

Diagnostic outputs (see Appendix B for details) suggest possible strong collinearity between the intercept, variable Proxy_mrl, variable SPS_no_mrl, and variable Proxy_count. Since Proxy_mrl has the least variation within the sample, we drop it to break the possible collinearity. Then we run the diagnostic procedure again (see Appendix B), possible strong collinearity emerges between variables $\mathrm{Ag}$, Food, Manu. So we drop variable Manu, because it seems to have relative high VIF and low explanation power. Following this second step, the diagnostic output suggests no additional serious collinearity problem (see Appendix B for details). In addition, we informally check the stability of the regression results by sequentially dropping each variable (results reported in Appendix C), and we believe collinearity issues have been addressed successfully.

Table 3 presents the results from the OLS, the robust, and the MNL regressions with clustered error structure. In OLS and robust regressions, the dependent variable is the t-value of the estimated technical-measure trade effects. Although we preserve the most variations possible to make trade effects from different studies comparable, a major limitation of using t-values is the difficulty in interpreting the coefficients. The results tell us which variables have significant impacts on the t-values and the direction of the impacts, but we need to know the current t-value to say more.

For example, given a negative coefficient of some variable, an increase in this variable makes the trade effects more negative significant or less positive significant, but we cannot tell whether it becomes negative significant, insignificant, or positive significant unless we have the current value of the t-value. The marginal effects are conditional on the current t-value. To facilitate the interpretation, we centered the sample size variable and aggregation level variable 
at the mean of the dataset, 14172.53 and 5.14, respectively. So we can interpret the intercept of the linear regression as conditional mean of the t-value when sample size and aggregation level are at the sample mean, and all categorical variables equal zero. We interpret the coefficients of

\section{Table 3: Regression results}

\begin{tabular}{|c|c|c|c|c|c|c|c|}
\hline \multirow[t]{2}{*}{ Explanatory Var. } & \multirow[t]{2}{*}{ OLS } & \multirow[t]{2}{*}{$\begin{array}{c}\text { Robust } \\
\text { Regression }\end{array}$} & \multicolumn{2}{|c|}{$\begin{array}{l}\text { Multinomial Logit } \\
\text { (MNL) }\end{array}$} & \multicolumn{3}{|c|}{$\begin{array}{c}\text { Marginal Effect of MNL } \\
\text { (conditional on sample means) }\end{array}$} \\
\hline & & & $\log \frac{\mathrm{P}(D=1)}{\mathrm{P}(D=2)}$ & $\log \frac{\mathrm{P}(D=3)}{\mathrm{P}(D=2)}$ & $\frac{\partial P_{1}}{\partial Z^{k}}$ & $\frac{\partial P_{2}}{\partial Z^{k}}$ & $\frac{\partial P_{3}}{\partial Z^{k}}$ \\
\hline \multirow[t]{2}{*}{ Intercept } & -0.11 & -0.11 & 1.88 & 0.56 & 0.4 & -0.38 & -0.02 \\
\hline & $(1.12)$ & $(0.73)$ & $(1.21)$ & $(0.93)$ & $(0.27)$ & $(0.26)$ & $(0.08)$ \\
\hline \multirow[t]{2}{*}{ Fix_country_pair } & $2.19 * * *$ & $2.89 * * *$ & $-1.81 * *$ & 0.17 & $-0.42 * *$ & $0.33 *$ & $0.09 *$ \\
\hline & $(0.72)$ & $(0.45)$ & $(0.83)$ & $(0.62)$ & $(0.18)$ & $(0.17)$ & $(0.05)$ \\
\hline \multirow[t]{2}{*}{ Panel_fix_time } & $-2.16^{* *}$ & $-1.79 * * *$ & $\mathrm{n} / \mathrm{a}$ & $\mathrm{n} / \mathrm{a}$ & $\mathrm{n} / \mathrm{a}$ & $\mathrm{n} / \mathrm{a}$ & $\mathrm{n} / \mathrm{a}$ \\
\hline & $(1.04)$ & $(0.66)$ & & & & & \\
\hline \multirow[t]{2}{*}{ Panel_var_time } & -1.16 & $-1.07 *$ & $1.68 * *$ & $-1.25^{*}$ & $0.44 * * *$ & -0.23 & $-0.20 * * *$ \\
\hline & $(0.91)$ & $(0.57)$ & $(0.76)$ & $(0.70)$ & $(0.17)$ & $(0.15)$ & $(0.06)$ \\
\hline \multirow[t]{2}{*}{ Zero_treated } & $-3.18 * * *$ & $-2.93 * * *$ & 0.42 & $0.88 * *$ & 0.06 & -0.13 & $0.08^{*}$ \\
\hline & $(0.57)$ & $(0.36)$ & $(0.43)$ & $(0.37)$ & $(0.10)$ & $(0.09)$ & $(0.04)$ \\
\hline \multirow[t]{2}{*}{$A g$} & $-0.86^{*}$ & $-0.93 * * *$ & 0.29 & $-1.03 * * *$ & 0.11 & 0.01 & $-0.12 * * *$ \\
\hline & $(0.49)$ & $(0.31)$ & $(0.41)$ & $(0.24)$ & $(0.08)$ & $(0.09)$ & $(0.02)$ \\
\hline \multirow[t]{2}{*}{ Food } & $-0.97 *$ & $-1.18^{* * *}$ & 0.68 & $-0.88 * *$ & $0.19^{*}$ & -0.07 & $-0.12 * *$ \\
\hline & $(0.49)$ & $(0.31)$ & $(0.46)$ & $(0.44)$ & $(0.10)$ & $(0.08)$ & $(0.05)$ \\
\hline \multirow[t]{2}{*}{$d e v \_S P S$} & $-3.56 * * *$ & $-2.53 * * *$ & $1.03 * *$ & 0.2 & $0.23 * *$ & $-0.20 * *$ & -0.02 \\
\hline & $(0.60)$ & $(0.38)$ & $(0.44)$ & $(0.58)$ & $(0.10)$ & $(0.10)$ & $(0.06)$ \\
\hline \multirow[t]{2}{*}{ Agg_hs_centered } & $0.73^{* * *}$ & $0.56^{* * *}$ & -0.1 & 0.02 & -0.02 & 0.02 & 0.01 \\
\hline & $(0.18)$ & $(0.12)$ & $(0.16)$ & $(0.18)$ & $(0.04)$ & $(0.03)$ & $(0.02)$ \\
\hline \multirow[t]{2}{*}{ Sample_centered } & 0.05 & -0.02 & $0.21 * *$ & $0.26^{* * *}$ & $0.04 * *$ & $-0.06^{* *}$ & $0.02 * * *$ \\
\hline & $(0.04)$ & $(0.02)$ & $(0.09)$ & $(0.09)$ & $(0.02)$ & $(0.02)$ & $(0.01)$ \\
\hline \multirow[t]{2}{*}{ Proxy_dummy } & $2.95 * * *$ & $1.74 * * *$ & $-2.22 * * *$ & $-2.09 * * *$ & $-0.42 * *$ & $0.55^{* * *}$ & $-0.13^{*}$ \\
\hline & $(0.87)$ & $(0.55)$ & $(0.82)$ & $(0.85)$ & $(0.19)$ & $(0.16)$ & $(0.08)$ \\
\hline \multirow[t]{2}{*}{ Proxy_count } & $2.22 * *$ & $2.12 * * *$ & $-2.27 * *$ & 0.73 & $-0.55 * * *$ & $0.38 *$ & $0.17 * * *$ \\
\hline & $(1.00)$ & $(0.63)$ & $(0.99)$ & $(0.76)$ & $(0.21)$ & $(0.21)$ & $(0.06)$ \\
\hline Proxy_freq & $\begin{array}{l}2.65 * * * \\
(0.91)\end{array}$ & $\begin{array}{c}2.17 * * * \\
(0.58)\end{array}$ & $\begin{array}{c}-1.48^{* *} \\
(0.75)\end{array}$ & $\begin{array}{c}-1.97 * * * \\
(0.60)\end{array}$ & $\begin{array}{l}-0.26 \\
(0.17)\end{array}$ & $\begin{array}{c}0.40^{* * *} \\
(0.15)\end{array}$ & $\begin{array}{c}-0.15^{* *} \\
(0.06)\end{array}$ \\
\hline \multirow[t]{2}{*}{ SPS_no_mrl } & $-1.13 *$ & $-0.81 * *$ & -0.48 & -0.4 & -0.09 & 0.12 & -0.02 \\
\hline & $(0.61)$ & $(0.39)$ & $(0.49)$ & $(0.40)$ & $(0.11)$ & $(0.10)$ & $(0.05)$ \\
\hline \multirow[t]{2}{*}{$T B T$} & -0.55 & $-1.18 * * *$ & -0.05 & -0.08 & -0.01 & 0.01 & -0.01 \\
\hline & $(0.64)$ & $(0.40)$ & $(0.64)$ & $(0.22)$ & $(0.15)$ & $(0.12)$ & $(0.04)$ \\
\hline $\mathrm{R}^{2}$ & 0.24 & 0.16 & \multicolumn{2}{|c|}{0.17} & & & \\
\hline Observations & 618 & 618 & \multicolumn{2}{|c|}{618} & & & \\
\hline
\end{tabular}


the variables as the impact on the $t$-values conditional on the $t$-value being equal to the intercept or the conditional sample mean described above. In addition, the MNL results help to sort out this issue as they provide estimated marginal effects.

We use the MNL regression together with robust regression to obtain a more precise interpretation of the results. For the most part, robust regression results and MNL results agree. In a few cases, MNL results indicate insignificant marginal effects of some variable(s) whereas robust regression shows significant impact of the same variable(s). This is caused by the limited variation of categorical dependent variables and the limited number of observations from splitting the data set into three zones. We use a specific example (figure 1 and table 4) to illustrate the situation later.

The variable Fix_country_pair controls for the correction of the "gold medal error." Robust regression shows that including the correction makes the conditional mean of $\mathrm{t}$-values more positive; MNL results show that the estimates in the literature with country-pair fixed effect are less likely to have negative significant technical measure trade effects, and more likely to have insignificant or positive significant technical measure trade effects than models estimated without the correction. The variable Panel_fix_time corresponds to the correction of the "bronze error" as well as the endogeneity of the technical measures. The results suggest that the latter correction makes the effects of technical measures more negative relative to the conditional average t-values. Investigations with panel data and time variation (Panel_var_time) are more likely to have negative significant trade effects, and less likely to have insignificant and positive significant trade effects. Their t-values tend to be more negative.

MNL results show that the treatment of zero-trade has a marginally small positive impact on the probability of getting positive estimates. However, the robust regression result seems to 
contradict that of the MNL estimation because it shows the conditional mean of t-values becomes more negative by retaining zero-trade. This is a rare case where robust regression results do not agree with MNL results, and the possible reason could be the limited variation of the categorical dependent variables. We illustrate this issue in figure 1 and table 4 below.

Figure1 shows that t-values are more closely clustered when zero trade is not treated, and t-values are more spread out in the negative range when zero trade is treated. Consequently, we have a negative significant coefficient for variable Zero_treated in the robust regression.

Figure 1: t-value against zero_treated dummy variable $(1=$ treated $)$

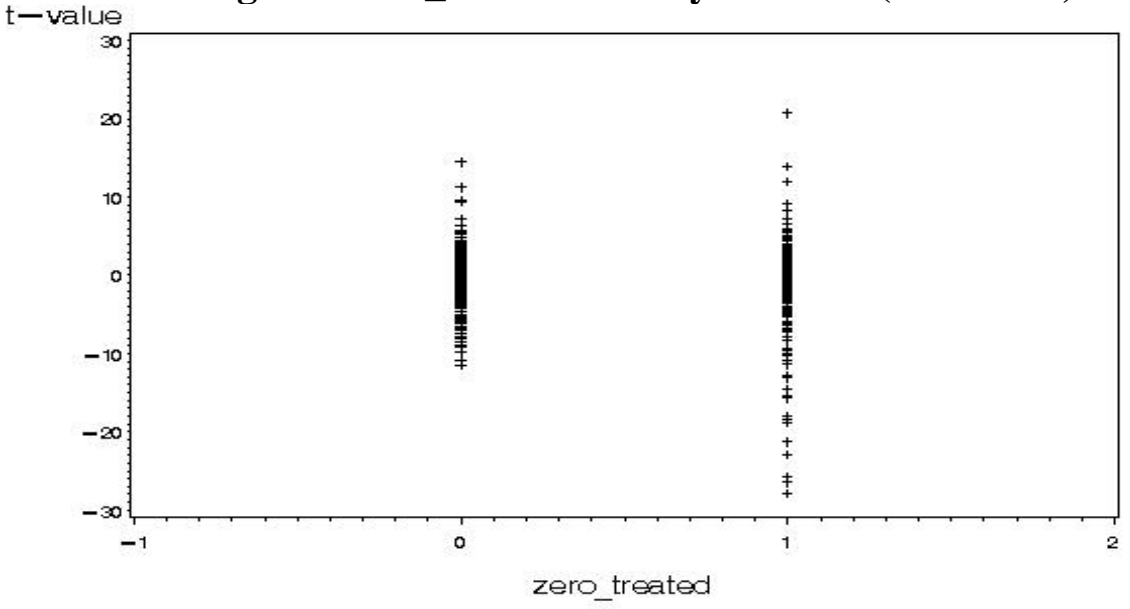

Table 4: Frequency of variable zero_treated in each category $D=1,2,3$

\begin{tabular}{|l|l|l|l|}
\hline \multicolumn{1}{|c|}{ Zero treated } & 0 & 1 & Total \\
\hline 1 & 121 & 88 & 209 \\
\hline 2 & 162 & 158 & 320 \\
\hline 3 & 44 & 45 & 89 \\
\hline Total & 327 & 291 & 618 \\
\hline
\end{tabular}

However, the relative position in the negative end of t-values is not shown in categorical variable $D$, because of its limited variation. Instead, the $D=3$ category has relative more observations ( 45 out of 291) when zero trade is treated, than when zero trade is not treated (44 out of 327). Hence, the MNL regression results suggest that treating zero trade increase the 
probability of having positive significant estimates.

For agriculture $(A g)$ and processed food products $($ Food $)$, the technical measure trade effects are less likely to be positive significant. We verify that the finding of SPS regulations having a trade impeding effect for agricultural products produced by developing exporters and going to developed importers is systematic. Both the robust regression and the MNL results show this effect to be significantly present. The result of interaction variable dev_SPS shows that the SPS trade effect from developing exporter to developed importer is more negatively affected and is most likely to be negatively significant, and less likely to be insignificant or positively significant.

The aggregation level of the data (Agg_hs_centered) is highly significant in the robust regression but not in the MNL. The more disaggregated the trade data, the more positive significant are the trade effects from the conditional mean of the t-values. The larger datasets (Sample_centered) tend to bring more conclusive results on the trade effects of technical measures as shown by the MNL results. The probability to have significant trade effects (either positive or negative) increases with the sample size. Not surprisingly, the OLS and robust regressions cannot capture this result.

Last and importantly, choosing the count proxy of technical measures (Proxy_count) is more likely to lead to positive or insignificant trade effects and less likely to have negative significant trade effects. Choosing the dummy proxy (Proxy_dummy) is more likely to lead to insignificant trade effects and less likely to have negative significant trade effects, while estimates obtained with the frequency proxy (Proxy freq) are less likely to be positive and more likely to be insignificant. Robust regression results suggest that these three proxies have a significant and positive influence on the estimated trade impact of technical measures. 
The robust regression cannot reject the null hypotheses that these three proxies are the same in terms of the positive and significant effect to the significance of trade effects. However, a similar set of tests in the MNL approach strongly rejects the null hypothesis that Proxy_dummy and Proxy_count have a similar impact on the probability of the technical measure estimates to fall in the third zone relative to the second zone $\left(P_{3} / P_{2}\right)$. The null hypothesis that Proxy-dummy and Proxy-freq are equal in their effect on $\left(P_{3} / P_{2}\right)$ cannot be rejected, nevertheless. In conclusion, these results are consistent with ruling out a negative influence of these proxies on estimated trade effects, although the two approaches disagree on their relative impacts. Finally, OLS and robust regression results suggest that SPS other than those proxied by MRLs (SPS_no $\left.{ }_{-} m r l\right)$ and TBT $(T B T)$ policies lead to more negative trade coefficients. However, MNL results do not suggest any significant patterns.

\section{Robustness Checks}

We consider two major robustness checks, one associated with the existence of influential observations, and another one based on the cut-off values used to separate the three MNL regions into which technical measure estimates fall (negative significant, insignificant, positive significant). First, due to the cluster-structure of our sample, we undertake influential data diagnostics based on clusters represented by the papers included in the dataset, instead of individual observations. We calculate standardized DFbetas and Cook's D statistics. The detailed analysis is shown in Appendix D. Following the rule of thumb on DFbetas and Cook's D, we flag possible influential clusters $1,5,8,21$, because associated DFbetas or Cook's Ds were higher than 1. To further check the influences of these papers, we drop one paper at a time and rerun the meta-analysis and compare regression results with those based on the full sample. 
These are shown in Appendix F for paper 1, and Appendix G for papers 5, 8, and 21.

Dropping observations from paper 1 causes complications with the estimates associated with variables Proxy_dummy, Proxy_count, and Proxy_freq, especially in the MNL model. This is due to a convergence problem in the MNL (the log likelihood does not converge). Variables Proxy_dummy, Proxy_count, and Proxy_freq are nearly co-linear once paper-1 observations are dropped (see Appendix E for collinearity diagnostics of the reduced sample). Results are stable to the deletions of observations from Papers 5, 8, or 21.

Second, we check whether our MNL regression results are robust to different cutoff points of the categorical dependent variable. In the previous MNL regressions, the categorical dependent variable equals to $-1,0,1$ when t-values are larger than 1.96 , within $(-1.96,1.96)$, and smaller than -1.96, respectively. Appendix H compares regression results for cut off points,+1.96 , and,+-1.64 . Changes in the regression results are small and qualitative results on determinants are essentially similar on signs, significance, and order of magnitude of the estimated coefficients. The only difference is that the intercept for the log of the probability to be negative relative to being insignificant $\left(\log \left(\mathrm{P}_{1} / \mathrm{P}_{2}\right)\right.$ is significantly positive, suggesting that estimates of trade effects are more likely to be negative. So we conclude that the choice of cutoff values is not a cause of concern.

\section{Conclusions}

We conducted a meta-analysis to explain the systematic variations found in estimated trade effects of technical measures using both data sampling and methodology differences. Although it is impossible to control for all the differences among the studies, we controlled for the determinants that are most likely to matter, based on theoretical findings as well as important 
conjectures found in the previous empirical literature.

Analyses of agriculture and food industries lead to estimates of trade effects of technical measures, which are less likely to be positive. Trade flows in these sectors tend to be more impeded by technical measures than do trade flows in other sectors. Further, we find systematic impeding effect of SPS regulations on agricultural exports sourced from developing countries and going to high-income countries. Both robust regression and MNL approaches sustain this important finding which suggests that SPS regulations are trade barriers rather than catalysts in the set of studies analyzed here. We find that models that control for the "multilateral resistance" terms using country-pair dummies are more likely to yield positive and significant estimates of trade effects of technical measures than those that do not control for multilateral resistance. Similarly, the former studies are less likely to yield negative significant trade effects than are the latter.

The evidence of the three technical measure proxies is mixed. The three proxies tend to have a positive effect on the estimates of trade effects of technical measures. No strong evidence shows that the three different forms of technical measure proxies (count, frequency, dummy) would lead to systematically different trade effects in the robust regression, however, the MNL results strongly suggest that studies based on a count proxy yield estimates that are more likely to be positive and much less likely to be negative. These two effects are the largest in magnitude for the count proxy. The results on proxies, although convoluted, are consistent with ruling out a negative influence of these proxies on the estimated trade effects of technical measures. The aggregation level of the trade data could also affect the estimated trade effects, and the more disaggregated data tend to provide more positive significant estimated trade effects of technical measures relative to the conditional sample mean of t-values. These effects were found in the 
robust regression results but could not be confirmed with the MNL approach because of lack of statistical significance.

In the future one could pool our dataset with studies analyzing multilateral, harmonized, and reciprocal technical measures and incorporate technical measure estimates associated with these standards. These standards have a different function with much potential to exhibit tradeexpanding ability and with ambiguous effects on cost of production. 


\section{References}

Anders, S., and J. A. Caswell. 2006. "Assessing the Impact of Stricter Food Safety Standards on Trade: HACCP in U.S. Seafood Trade with the Developing World," Selected paper of the 2006 American Agricultural Economics Association Annual Meetings.

Anderson, J. E. 1979. "A Theoretical Foundation for the Gravity Equation," American Economic Review 69(1): 106-16.

Anderson, J. E. and van Wincoop, E. 2003. "Gravity with Gravitas: A Solution to the Border Puzzle," American Economic Review 93(1): 170-192.

Anderson, J.E. and van Wincoop, E. 2004. "Trade Costs," Journal of Economic Literature, vol. 42(3), pages 691-751, September.

Babool, A., and Reed, M. 2007. "Food Safety Standards and Export competitiveness in the Food and Processed Food Industries in Asia-Pacific Countries," Paper prepared for presentation at the Mediterranean Conference of Agro-Food Social Scientists. $103^{\text {rd }}$ EAAE Seminar 'Adding Value to the Agro-Food Supply Chain in the Future EuroMediterranean Space'.

Baier, S. L., and Bergstrand, J. H. 2007. "Do free trade agreements actually increase members' international trade?," Journal of International Economics 71(1): 72-95.

Baldwin, R., and Taglioni, D. 2006. "Gravity for Dummies and Dummies for Gravity Equations," NBER Working Papers 12516.

Beghin, J. C., and Bureau, J.C. 2001. "Quantitative Policy Analysis of Sanitary, Phytosanitary and Technical Barriers to Trade," Economie Internationale issue 3(no 87): 107-130.

Belsley, D. A., Kuh, E. and Welsch, R. E. 1980. Regression Diagnostics. New York: Wiley.

Blind, K. 2001. "The impacts of innovations and standards on trade of measurement and testing products: empirical results of Switzerland's bilateral flows with Germany, France, and the UK, ”Information Economics and Policy 13: 439-460.

Blind, K., and Jungmittag, A. 2005. "Trade and the impact of innovations and standards: the case of Germany and the UK," Applied Economics 37: 1385-1398.

Chen, C., Yang, J., and Findlay, C. 2008. "Measuring the Effect of Food Safety Standards on China's Agricultural Exports," Review of World Economics/Weltwirtschaftliches Archiv 144 (1): 83-106.

Chen, N. 2004. "Intra-national versus international trade in the European Union: why do national borders matter?” Journal of International Economics 63: 93-118.

Chevassus-Lozza, E., Latouche, K., Majkovic, D., and Unguru, M. 2008. “The Importance of EU-15 Borders for CEECs Agri-food Exports: The Role of Tariffs and Non-tariff Measures in the Pre-accession Period". Food Policy 33(6): 595-606.

Deardorff, A., and Stern, R. 1998. The Measurement of Non-Tariff Barriers. OECD Economics Department Working Papers No. 179, OECD Paris.

Disdier, A.-C., Fekadu, B., Murillo, C., and Wong, S.A. 2008a. "Trade Effects of SPS and TBT measures on Tropical Products," ICTSD Issue Paper \# 12. 
Disdier, A.-C., and Fontagné, L. 2008. "Trade Impact of European Measures on GMOs Condemned by the WTO Panel," 2008 International Congress, August 26-29, Ghent, Belgium 44392, European Association of Agricultural Economists.

Disdier, A.-C., Fontagné, L., and Mimouni, M. 2008b. “The Impact of Regulations on Agricultural Trade: Evidence from the SPS and TBT Agreements," American Journal of Agricultural Economics 90(2): 336-350.

Disdier, A.-C., and Head, K. 2008. "The Puzzling Persistence of the Distance Effect on Bilateral Trade," The Review of Economics and Statistics 90(1): 37-48.

Disdier, A.-C., and Marette, S. 2010. "The Combination of Gravity and Welfare Approaches for Evaluating Non-tariff Measures," American Journal of Agricultural Economics 92(3): 713-726.

Evenett, S.J., and Keller, W. 2002. "On Theories Explaining the Success of the Gravity Equation," Journal of Political Economy vol. 110(2): 281-316.

Feenstra, R. 2004. Advanced International Trade, Princeton, N.J.: Princeton University Press. Fontagné, L., Mimouni, M., and Pasteels J.M. 2005. "Estimating the Impact of Environmental SPS and TBT on International Trade," Integration and Trade 22: 7-37.

Fontagné, L., Mayer, T., and Zignago, S. 2005. "Trade in the Triad: How Easy is the Access to Large Markets?” Canadian Journal of Economics 38(4): 1401-1430.

Ganslandt, M. and Markusen, J. R. 2001. "Standards and Related Regulations in International Trade: A Modeling Approach," NBER Working Papers 8346.

Gebrehiwet, Y., Ngqangweni, S., and Kirsten, J.F. 2007. "Quantifying the Trade Effect of Sanitary and Phytosanitary Regulations of OECD Countries on South African Food Exports," Agrekon 46(1): 23-39.

Harrigan, J. 1993 "OECD Imports and Trade Barriers in 1983," Journal of International Economics 34(1-2): 91-111.

Harrigan, James, 1996. "Openness to trade in manufactures in the OECD," Journal of International Economics 40(1-2): 23-39.

Haveman, J. D., Nair-Reichert, U., and Thursby, J.G. 2003. "How Effective are Trade Barriers? An Empirical Analysis of Trade Reduction, Diversion, and Compression," The Review of Economics and Statistics 85(2): 480-485.

Helpman, E. 1987. "Imperfect competition and international trade: Opening remarks," European Economic Review, vol. 31(1-2): 77-81.

Helpman, E, Melitz, M., and Rubinstein, Y. 2008. "Estimating Trade Flows: Trading Partners and Trading Volumes," The Quarterly Journal of Economics 123(2): 441-487.

Hillberry, R. H. 2002. "Aggregation bias, compositional change, and the border effect," Canadian Journal of Economics 35(3): 517-530.

Hummels, D. 1999. "Toward a Geography of Trade Costs," GTAP Working Papers 1162, Center for Global Trade Analysis, Department of Agricultural Economics, Purdue University.

Jayasinghe, S., Beghin, J.C., and Moschini, G.C. Forthcoming. "Determinants of World Demand for U.S. Corn Seeds: The Role of Trade Costs," American Journal of Agricultural 


\section{Economics.}

Kee H. L., Nicita, A., and Olarreaga, M. 2009. "Estimating Trade Restrictiveness Indices," Economic Journal 119: 1-28.

Lambert, D. 1992. "Zero-Inflated Poisson Regression, With an Application to Defects in Manufacturing," Technometrics 34: 1-14.

Lee, J.-W., and Swagel, P. 1997. "Trade Barriers and Trade Flows across Countries and Industries," The Review of Economics and Statistics 79(3): 372-382.

Martin, W., and Pham, C. S. 2008. "Estimating the Gravity Equation when Zero Trade Flows are Frequent," MPRA Paper 9453, University Library of Munich, Germany.

Maskus, K. E., Wilson, J. S., and Otsuki, T. 2000. "Quantifying the impact of technical barriers to trade: a framework for analysis," Policy Research Working Paper Series 2512, The World Bank.

Moenius, J. 2004. "Information versus Product Adaptation: The Role of Standards in Trade," working paper.

Moenius, J. 2007a. "The Good, the Bad and the Ambiguous: Standards and Trade in Agricultural Products," working paper.

Moenius, J. 2007b. "Do National Standards Hinder or Promote Trade in Electrical Products?" International Standardization as a Strategic Tool, commended paper of the IEC Centennial Challenge, Geneva.

Nardella, M., and Boccaletti, S. 2003. "The Impact of Technical Barriers on Us-Eu Agro-Food Trade," 2003 Annual meeting, July 27-30, Montreal, Canada, American Agricultural Economics Association.

Nardella, M., and Boccaletti, S. 2004. "The Impact of EU And US Agro-Food Non Tariff Measures On Exports From Developing Countries," 2004 Annual meeting, August 1-4, Denver, CO, American Agricultural Economics Association.

Nardella, M., and Boccaletti, S. 2005. "The NAFTA Agreement and Market Integration Among Canada, US and Mexico: The Role of Non-Tariff Measures," 2005 Annual meeting, July 24-27, Providence, RI, American Agricultural Economics Association.

Nguyen, A.V.T., and Wilson, N.L.W. 2009. "Effects of Food Safety Standards on Seafood Exports to US, EU and Japan," Southern Agricultural Economics Association Annual Meeting.

Olper, A., and Raimondi, V. 2008. "Explaining National Border Effects in the QUAD Food Trade". Journal of Agricultural Economics 59(3): 436-62.

Otsuki, T., Wilson, J.S., and Sewadeh, M. 2001a. "What price precaution? European harmonization of aflatoxin regulations and African groundnut exports," European Review of Agricultural Economics 28(2): 263-283.

Otsuki, T., Wilson, J.S., and Sewadeh, M. 2001b. "A race to the top? A case study of food safety standards and African exports," Policy Research Working Paper Series 2563, The World Bank.

Redding, S., and Venables, A. J., 2004. "Economic geography and international inequality," 
Journal of International Economics 62(1): 53-82.

Rose, A. K., and van Wincoop, E. 2001. "National Money as a Barrier to International Trade: The Real Case for Currency Union," American Economic Review 91(2): 386-390.

Silva, J.M.C.S., and Tenreyro, S. 2006. "The Log of Gravity," The Review of Economics and Statistics 88(4): 641-658.

Scheepers, S., Jooste, A., and Alemu, ZG. 2007. "Quantifying the impact of phytosanitary standards with specific reference to MRLs on the trade flow of South African avocados to the EU," Agrekon 46(2): 260-273.

Swann, P., Temple, P., and Shurmer, M. 1996. "Standards and Trade Performance: The UK Experience," Economic Journal 106(438): 1297-1313.

Trefler, D. 1993. "Trade Liberalization and the Theory of Endogenous Protection: An Econometric Study of U.S. Import Policy," Journal of Political Economy 101(1): 138-60.

Wilson, J. S., and Otsuki, T. 2001. "Global trade and food safety - winners and losers in a fragmented system," Policy Research Working Paper Series 2689, The World Bank.

Wilson, J.S., and Otsuki, T. 2004. "To spray or not to spray: pesticides, banana exports, and food safety," Food Policy 29(2): 131-146.

Wilson, JS, Otsuki, T., and Majumdsar, B. 2003. "Balancing food safety and risk: do drug residue limits affect international trade in beef?" Journal of International Trade \&Economic Development 12(4): 377-402. 


\section{Appendix to "A Meta-Analysis of Estimates of the Impact of Technical Barriers to Trade" (Not intended for publication) \\ Appendix A: Frequency of Zero-treatment procedures}

\begin{tabular}{|l|l|l|l|l|l|}
\hline Procedures & $\begin{array}{l}\text { Frequency } \\
\text { in } \\
\text { observations }\end{array}$ & $\begin{array}{l}\text { Frequency } \\
\text { in papers }\end{array}$ & $\begin{array}{l}\text { Negative } \\
\text { significant } \\
\text { estimate (\%) }\end{array}$ & $\begin{array}{l}\text { Insignifica } \\
\text { nt estimate } \\
(\%)\end{array}$ & $\begin{array}{l}\text { Positive } \\
\text { significant } \\
\text { estimate } \\
(\%)\end{array}$ \\
\hline $\begin{array}{l}\text { Adding arbitrary } \\
\text { small numbers }\end{array}$ & 4 & 1 & 100 & 0 & 0 \\
\hline PPML & 48 & 2 & 58 & 42 & 0 \\
\hline $\begin{array}{l}\text { Heckman two } \\
\text { stage }\end{array}$ & 7 & 2 & 71 & 0 & 29 \\
\hline Tobit & 232 & 4 & 22 & 59 & 19 \\
\hline Truncation & 327 & 18 & 37 & 50 & 13 \\
\hline Total & 618 & 27 & & & \\
\hline
\end{tabular}

\section{Appendix B: Collinearity diagnostic and Correction}

\section{B.1 Before correcting for multi-collinearity}

$\begin{array}{lc}\text { Variable } & \begin{array}{c}\text { Variance } \\ \text { Inflation }\end{array} \\ \text { Intercept } & 0 \\ \text { AG } & 4.25936 \\ \text { FOOD } & 3.39804 \\ \text { MANU } & 4.15449 \\ \text { PROXY_DU } & 8.84544 \\ \text { PROXY_CO } & 14.90265 \\ \text { PROXY_FR } & 8.68433 \\ \text { PROXY_MR } & 4.38692 \\ \text { sample_centered } & 1.85510 \\ \text { SPS_no_mrl } & 3.47567 \\ \text { TBT } & 4.53456 \\ \text { agg_hs_centered } & 4.10358 \\ \text { panel_fix_time } & 4.37959 \\ \text { panel_var_time } & 4.13932 \\ \text { fix_pair } & 5.81697 \\ \text { zero_treat } & 3.20478 \\ \text { dev_SPS } & 2.77476\end{array}$

\section{Collinearity Diagnostics}

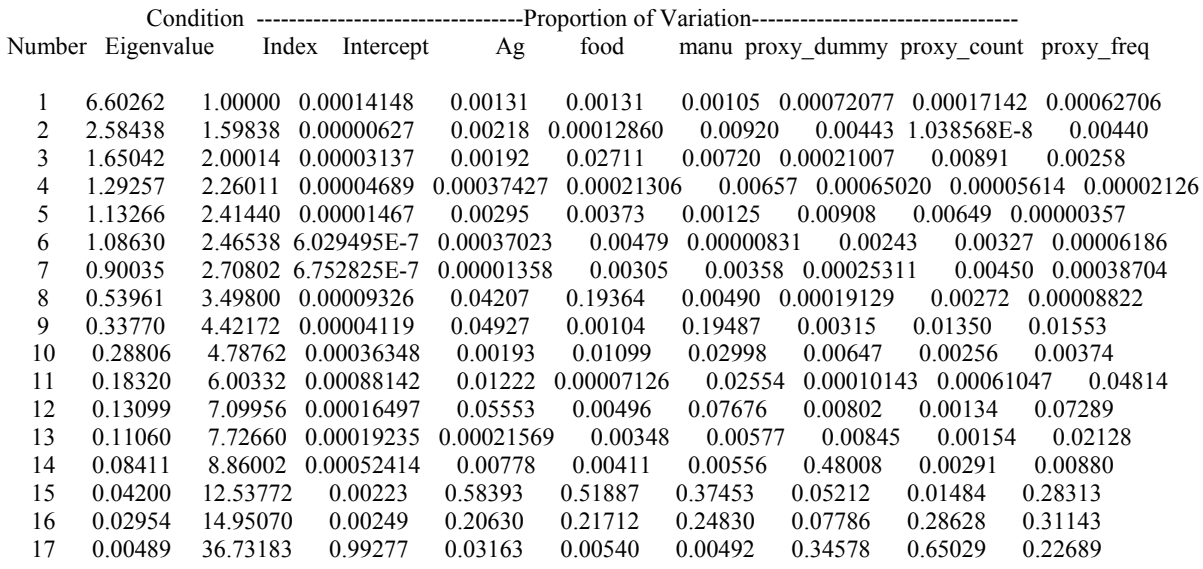


Collinearity Diagnostics

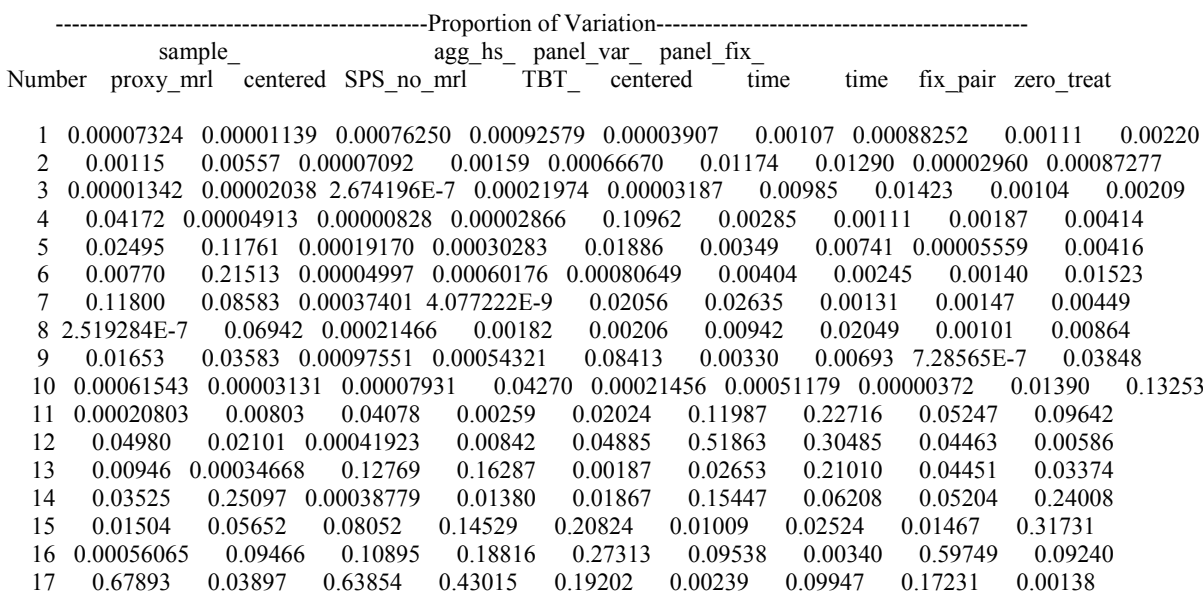

-Proportion of Variation-

Number dev_SPS

$\begin{array}{cc}1 & 0.00180 \\ 2 & 0.00557 \\ 3 & 0.01112 \\ 4 & 0.00001726 \\ 5 & 0.02457 \\ 6 & 0.05624 \\ 7 & 0.00082384 \\ 8 & 0.00092178 \\ 9 & 0.00096003 \\ 10 & 0.34274 \\ 11 & 0.00024071 \\ 12 & 0.00698 \\ 13 & 0.07420 \\ 14 & 0.37802 \\ 15 & 0.04352 \\ 16 & 0.00513 \\ 17 & 0.04716\end{array}$

\section{B.2 Dropping proxy_mrl \\ Variance}

Variable Inflation

Intercept $\quad 0$

AG 4.25826

FOOD $\quad 3.39564$

MANU 4.15444

PROXY_DU $\quad 5.85680$

PROXY_CO 8.00077

PROXY FR 7.75447

sample_centered 1.80913

SPS_no_mrl 1.63325

TBT $\quad 3.09905$

agg_hs_centered 3.64273

panel_fix_time 4.35477

panel var time 4.13466

fix_pair 5.35399

zero_treat 3.18337

dev_SPS 2.55818 


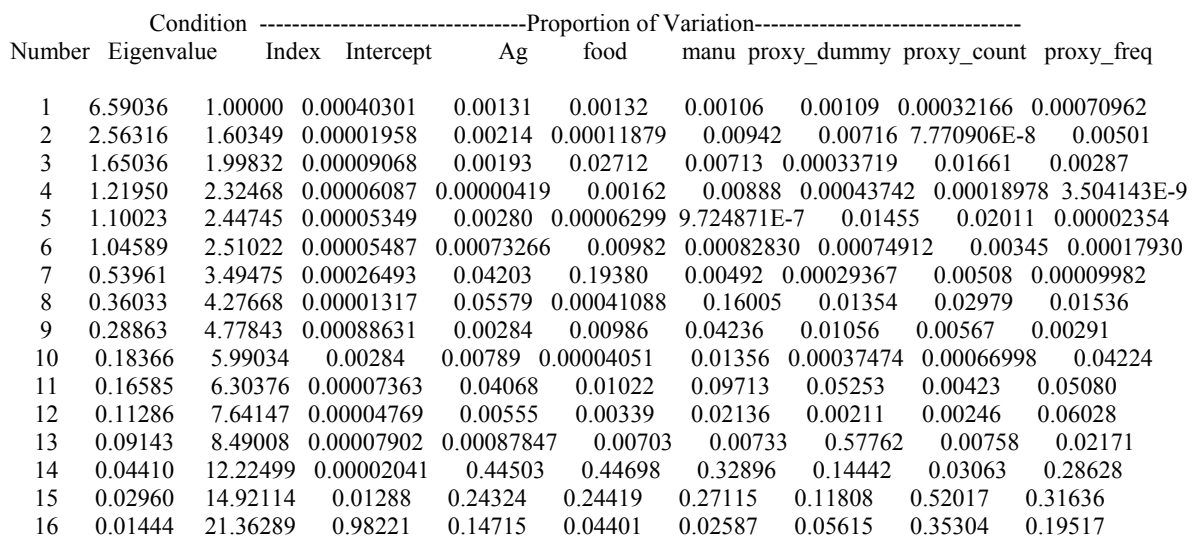

Collinearity Diagnostics

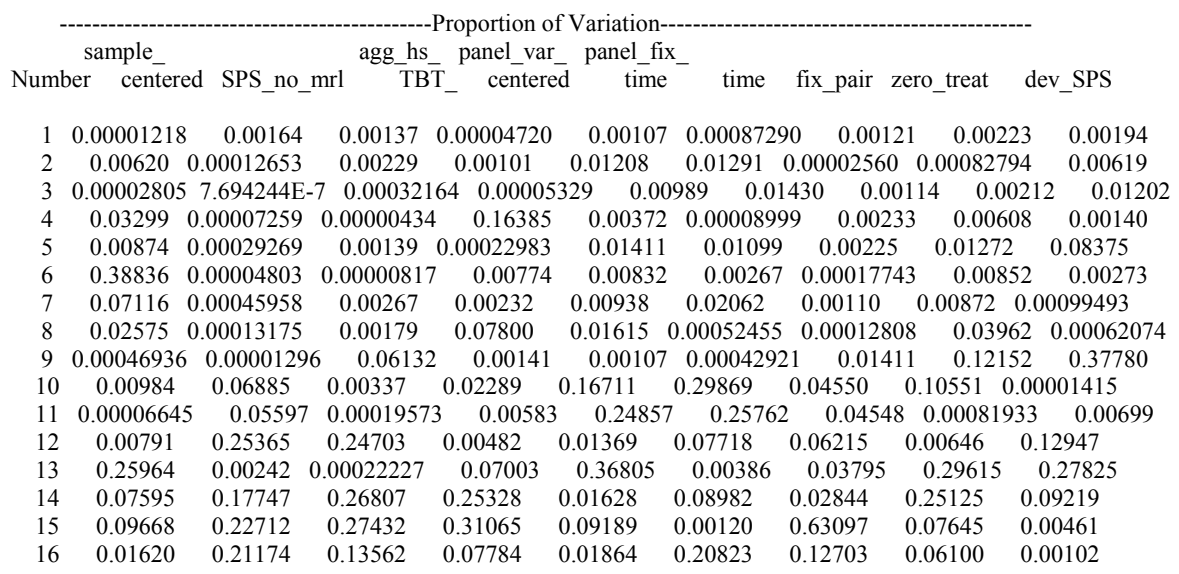

\section{B.3 Dropping the dummy for manufacturing products}

$\begin{array}{lc}\text { Variable } & \begin{array}{c}\text { Variance } \\ \text { Inflation }\end{array} \\ \text { Intercept } & 0 \\ \text { AG } & 2.25894 \\ \text { FOOD } & 1.94903 \\ \text { PROXY_DU } & 5.81106 \\ \text { PROXY_CO } & 7.16239 \\ \text { PROXY_FR } & 7.69855 \\ \text { sample_centered } & 1.66158 \\ \text { SPS_no_mrl } & 1.62968 \\ \text { TBT } & 3.09000 \\ \text { TBT } & \end{array}$

agg_hs_centered 2.58175

panel fix time 4.34327

panel_var_time 4.11025

fix_pair $\quad 4.60602$

zero_treat 3.12483

dev_SPS 2.48637 


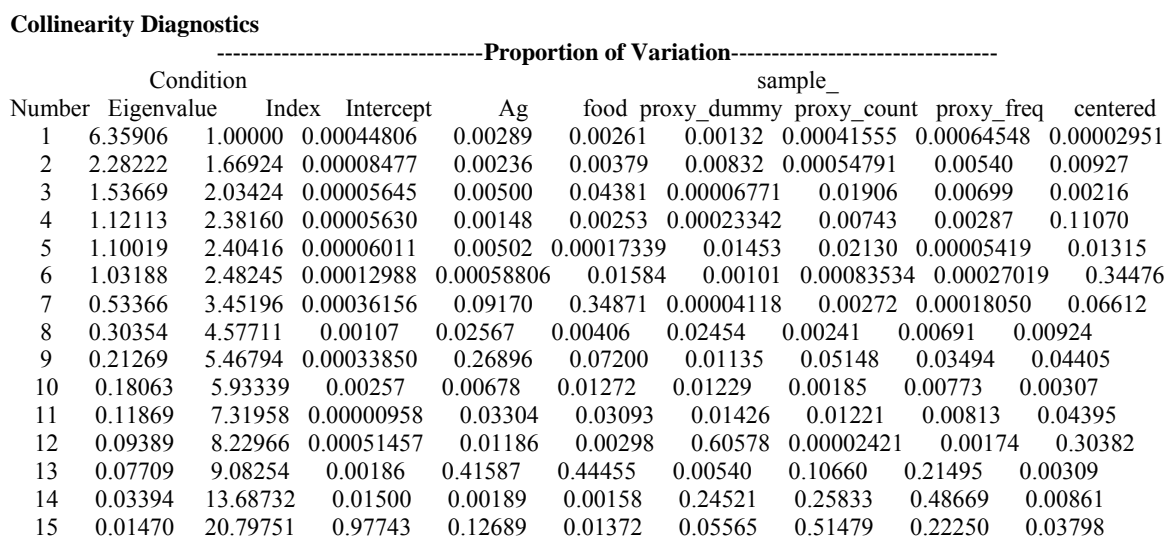

Collinearity Diagnostics

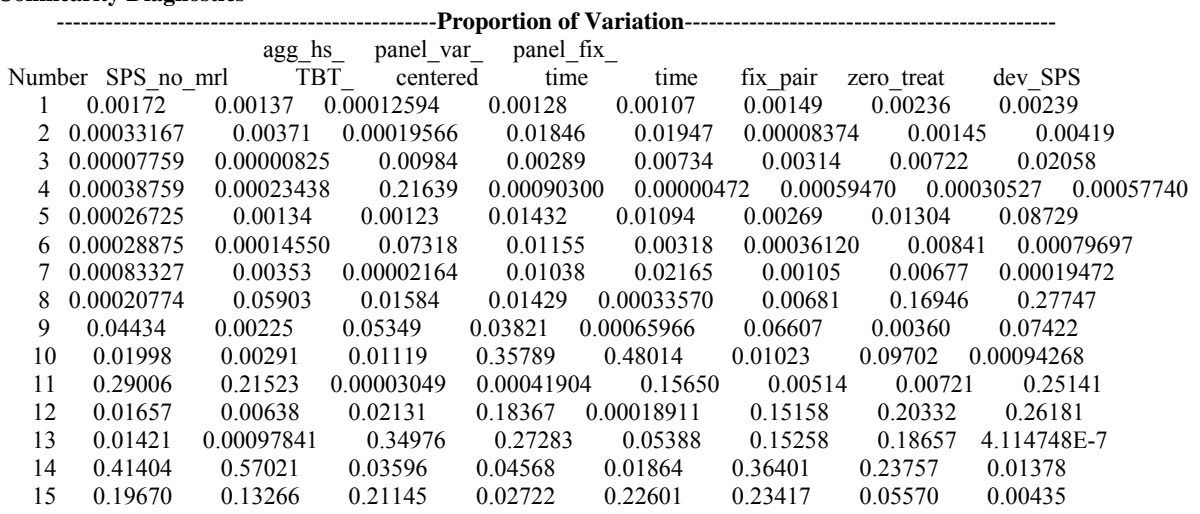

Appendix C. Sensitivity of results to variable deletion (one by one)

\begin{tabular}{|c|c|c|c|c|c|c|}
\hline \multirow[t]{2}{*}{ Explanatory Var. } & \multicolumn{2}{|c|}{ Multinomial Logit (all variables) } & \multicolumn{2}{|c|}{ Multinomial Logit } & \multicolumn{2}{|c|}{ Multinomial Logit } \\
\hline & $\log \left(\frac{\mathrm{P}(D=1)}{\mathrm{P}(D=2)}\right)$ & & $\log \left(\frac{\mathrm{P}(D=1)}{\mathrm{P}(D=2)}\right)$ & $\left(\frac{\mathrm{P}(D=3)}{\mathrm{P}(D=2)}\right)$ & $\log \left(\frac{\mathrm{P}(D=1)}{\mathrm{P}(D=2)}\right)$ & $\left(\frac{\mathrm{P}(D=3)}{\mathrm{P}(D=2)}\right)$ \\
\hline Intercept & $\begin{array}{c}1.88 \\
(1.21)\end{array}$ & $\begin{array}{c}0.56 \\
(0.93)\end{array}$ & $\begin{array}{c}2.15 * * \\
(1.11)\end{array}$ & $\begin{array}{l}-0.36 \\
(0.99)\end{array}$ & $\begin{array}{c}2.14 * * \\
(1.10)\end{array}$ & $\begin{array}{c}0.37 \\
(0.90)\end{array}$ \\
\hline$A g$ & $\begin{array}{c}0.29 \\
(0.41)\end{array}$ & $\begin{array}{c}-1.03 * * * \\
(0.24)\end{array}$ & & & $\begin{array}{l}-0.05 \\
(0.34)\end{array}$ & $\begin{array}{c}-0.60 * * \\
(0.25)\end{array}$ \\
\hline Food & $\begin{array}{c}0.68 \\
(0.46)\end{array}$ & $\begin{array}{c}-0.88^{* *} \\
(0.44)\end{array}$ & $\begin{array}{c}0.55 \\
(0.40)\end{array}$ & $\begin{array}{l}-0.36 \\
(0.59)\end{array}$ & & \\
\hline Proxy_dummy & $\begin{array}{c}-2.22 * * * \\
(0.82)\end{array}$ & $\begin{array}{c}-2.09 * * * \\
(0.85)\end{array}$ & $\begin{array}{c}-2.29 * * * \\
(0.78)\end{array}$ & $\begin{array}{c}-2.25 * * \\
(0.96)\end{array}$ & $\begin{array}{c}-2.22 * * * \\
(0.76)\end{array}$ & $\begin{array}{c}-2.37 * * * \\
(0.90)\end{array}$ \\
\hline Proxy_count & $\begin{array}{c}-2.27 * * \\
(0.99)\end{array}$ & $\begin{array}{c}0.73 \\
(0.76)\end{array}$ & $\begin{array}{c}-2.24 * * \\
(0.98)\end{array}$ & $\begin{array}{c}0.54 \\
(0.97)\end{array}$ & $\begin{array}{c}-1.89^{* *} \\
(0.94)\end{array}$ & $\begin{array}{c}0.27 \\
(0.75)\end{array}$ \\
\hline Proxy_freq & $\begin{array}{c}-1.48 * * \\
(0.75)\end{array}$ & $\begin{array}{c}-1.97 * * * \\
(0.60)\end{array}$ & $\begin{array}{c}-1.68 * * * \\
(0.66)\end{array}$ & $\begin{array}{l}-1.16^{*} \\
(0.64)\end{array}$ & $\begin{array}{c}-1.79 * * * \\
(0.73)\end{array}$ & $\begin{array}{c}-1.39 * * * \\
(0.56)\end{array}$ \\
\hline Sample_centered & $\begin{array}{c}0.02 * * \\
(0.01)\end{array}$ & $\begin{array}{c}0.03 * * * \\
(0.01)\end{array}$ & $\begin{array}{c}0.02 * * * \\
(0.01)\end{array}$ & $\begin{array}{c}0.03 * * * \\
(0.01)\end{array}$ & $\begin{array}{c}0.02 * * * \\
(0.01)\end{array}$ & $\begin{array}{c}0.03 * * * \\
(0.01)\end{array}$ \\
\hline SPS_no_mrl & $\begin{array}{l}-0.48 \\
(0.49)\end{array}$ & $\begin{array}{l}-0.40 \\
(0.40)\end{array}$ & $\begin{array}{l}-0.53 \\
(0.50)\end{array}$ & $\begin{array}{l}-0.29 \\
(0.39)\end{array}$ & $\begin{array}{l}-0.51 \\
(0.47)\end{array}$ & $\begin{array}{l}-0.45 \\
(0.38)\end{array}$ \\
\hline$T B T$ & $\begin{array}{l}-0.05 \\
(0.64)\end{array}$ & $\begin{array}{l}-0.08 \\
(0.22)\end{array}$ & $\begin{array}{l}-0.08 \\
(0.65)\end{array}$ & $\begin{array}{c}0.03 \\
(0.23)\end{array}$ & $\begin{array}{l}-0.04 \\
(0.62)\end{array}$ & $\begin{array}{l}-0.11 \\
(0.22)\end{array}$ \\
\hline Agg_hs_centered & $\begin{array}{l}-0.10 \\
(0.16)\end{array}$ & $\begin{array}{c}0.02 \\
(0.18)\end{array}$ & $\begin{array}{l}-0.11 \\
(0.15)\end{array}$ & $\begin{array}{c}0.06 \\
(0.21)\end{array}$ & $\begin{array}{l}-0.17 \\
(0.15)\end{array}$ & $\begin{array}{c}0.13 \\
(0.18)\end{array}$ \\
\hline Panel_var_time & $\begin{array}{l}1.68 * * \\
(0.76)\end{array}$ & $\begin{array}{l}1.68 * * \\
(0.76)\end{array}$ & $\begin{array}{l}1.70 * * \\
(0.74)\end{array}$ & $\begin{array}{l}-0.80 \\
(0.83)\end{array}$ & $\begin{array}{l}1.39 * * \\
(0.69)\end{array}$ & $\begin{array}{l}-0.60 \\
(0.68)\end{array}$ \\
\hline Fix_country_pair & $\begin{array}{c}-1.81 * * \\
(0.83)\end{array}$ & $\begin{array}{c}-1.81 * * \\
(0.83)\end{array}$ & $\begin{array}{c}-1.78 * * \\
(0.81)\end{array}$ & $\begin{array}{c}0.19 \\
(0.76)\end{array}$ & $\begin{array}{c}-1.61 * * \\
(0.77)\end{array}$ & $\begin{array}{c}0.02 \\
(0.67)\end{array}$ \\
\hline Zero_treated & $\begin{array}{c}0.42 \\
(0.43)\end{array}$ & $\begin{array}{c}0.42 \\
(0.43)\end{array}$ & $\begin{array}{c}0.51 \\
(0.39)\end{array}$ & $\begin{array}{c}0.41 \\
(0.44)\end{array}$ & $\begin{array}{c}0.62 \\
(0.38)\end{array}$ & $\begin{array}{c}0.43 \\
(0.34)\end{array}$ \\
\hline dev_SPS & $\begin{array}{l}1.03 * * \\
(0.44)\end{array}$ & $\begin{array}{l}1.03 * * \\
(0.44)\end{array}$ & $\begin{array}{c}1.10 * * * \\
(0.40)\end{array}$ & $\begin{array}{c}0.11 \\
(0.66)\end{array}$ & $\begin{array}{c}1.19 * * * \\
(0.39)\end{array}$ & $\begin{array}{c}0.13 \\
(0.65)\end{array}$ \\
\hline
\end{tabular}


Appendix C. Sensitivity of results to variable deletion (one by one) (cont.)

\begin{tabular}{|c|c|c|c|c|c|c|c|c|}
\hline \multirow{2}{*}{$\begin{array}{l}\text { Explanatory } \\
\text { Var. }\end{array}$} & \multicolumn{2}{|c|}{ Multinomial Logit } & \multicolumn{2}{|c|}{ Multinomial Logit } & \multicolumn{2}{|c|}{ Multinomial Logit } & \multicolumn{2}{|c|}{ Multinomial Logit } \\
\hline & $\log \left(\frac{\mathrm{P}(D=1)}{\mathrm{P}(D=2)}\right)$ & $\left(\frac{\mathrm{P}(D=3)}{\mathrm{P}(D=2)}\right)$ & $\log \left(\frac{\mathrm{P}(D=1)}{\mathrm{P}(D=2)}\right)$ & $\left(\frac{\mathrm{P}(D=3)}{\mathrm{P}(D=2)}\right)$ & $\log \left(\frac{\operatorname{Pr}(D=1)}{\operatorname{Pr}(D=2)}\right)$ & $\left(\frac{\mathrm{P}(D=3)}{\mathrm{P}(D=2)}\right)$ & $\log \left(\frac{\mathrm{P}(D=1)}{\mathrm{P}(D=2)}\right)$ & $\left(\frac{\mathrm{P}(D=3)}{\mathrm{P}(D=2)}\right)$ \\
\hline Intercept & $\begin{array}{r}0.75 \\
(1.02)\end{array}$ & $\begin{array}{r}-0.44 \\
(1.02)\end{array}$ & $\begin{array}{r}0.4 \\
(0.91)\end{array}$ & $\begin{array}{r}1.18^{* * * *} \\
(0.42)\end{array}$ & $\begin{array}{r}1.09 \\
(1.04)\end{array}$ & $\begin{array}{r}-0.64 \\
(0.99)\end{array}$ & $\begin{array}{r}1.68 \\
(1.26)\end{array}$ & $\begin{array}{r}0.87 \\
(1.02)\end{array}$ \\
\hline$A g$ & $\begin{array}{r}0.43 \\
(0.44)\end{array}$ & $\begin{array}{r}-1.03 * * * \\
(0.27)\end{array}$ & $\begin{array}{r}0.19 \\
(0.47)\end{array}$ & $\begin{array}{r}-1.05 * * * \\
(0.26)\end{array}$ & $\begin{array}{l}0.54^{*} \\
(0.33)\end{array}$ & $\begin{array}{r}-0.72 * * \\
(0.35)\end{array}$ & $\begin{array}{r}0.44 \\
(0.44)\end{array}$ & $\begin{array}{r}-0.92 * * * \\
(0.34)\end{array}$ \\
\hline Food & $\begin{array}{r}0.72 \\
(0.48)\end{array}$ & $\begin{array}{r}-0.94 * * * \\
(0.48)\end{array}$ & $\begin{array}{r}0.36 \\
(0.59)\end{array}$ & $\begin{array}{r}-0.83^{* *} \\
(0.39)\end{array}$ & $\begin{array}{r}0.84 * * \\
(0.40)\end{array}$ & $\begin{array}{l}-0.66 \\
(0.43)\end{array}$ & $\begin{array}{l}0.83 * \\
(0.45)\end{array}$ & $\begin{array}{r}-0.71 \\
(0.48)\end{array}$ \\
\hline Proxy_dummy & & & $\begin{array}{l}-1.04 * \\
(0.55)\end{array}$ & $\begin{array}{r}-2.44 * * \\
(1.01)\end{array}$ & $\begin{array}{r}-1.51 * * \\
(0.72)\end{array}$ & $\begin{array}{l}-1.16 \\
(0.84)\end{array}$ & $\begin{array}{r}-1.95 * * * \\
(0.72)\end{array}$ & $\begin{array}{r}-1.27 \\
(0.80)\end{array}$ \\
\hline Proxy_count & $\begin{array}{l}-0.96 \\
(0.84)\end{array}$ & $\begin{array}{r}1.86 * * \\
(0.93)\end{array}$ & & & $\begin{array}{l}-1.23^{*} \\
(0.69)\end{array}$ & $\begin{array}{r}2.14 * * * \\
(0.83)\end{array}$ & $\begin{array}{r}-2.50 * * * \\
(0.99)\end{array}$ & $\begin{array}{r}-0.03 \\
(1.04)\end{array}$ \\
\hline Proxy_freq & $\begin{array}{l}-0.58 \\
(0.70)\end{array}$ & $\begin{array}{r}-1.33 * \\
(0.70)\end{array}$ & $\begin{array}{l}-0.39 \\
(0.47)\end{array}$ & $\begin{array}{r}-2.45 * * * \\
(0.63)\end{array}$ & & & $\begin{array}{r}-1.65^{* *} \\
(0.83)\end{array}$ & $\begin{array}{r}-2.50 * * * \\
(0.85)\end{array}$ \\
\hline Sample_centered & $\begin{array}{r}0.01 \\
(0.01)\end{array}$ & $\begin{array}{r}0.02 \\
(0.01)\end{array}$ & $\begin{array}{r}0.02 * * \\
(0.01)\end{array}$ & $\begin{array}{r}0.03 * * * \\
(0.01)\end{array}$ & $\begin{array}{r}0.03 * * \\
(0.01)\end{array}$ & $\begin{array}{r}0.03 * * * \\
(0.01)\end{array}$ & & \\
\hline SPS_no_mrl & $\begin{array}{l}-0.57 \\
(0.50)\end{array}$ & $\begin{array}{l}-0.37 \\
(0.52)\end{array}$ & $\begin{array}{l}-0.41 \\
(0.49)\end{array}$ & $\begin{array}{r}-0.35 \\
(0.40)\end{array}$ & $\begin{array}{l}-0.71 \\
(0.46)\end{array}$ & $\begin{array}{l}-0.61 \\
(0.41)\end{array}$ & $\begin{array}{r}-0.43 \\
(0.50)\end{array}$ & $\begin{array}{r}-0.35 \\
(0.44)\end{array}$ \\
\hline$T B T$ & $\begin{array}{l}-0.30 \\
(0.74)\end{array}$ & $\begin{array}{l}-0.19 \\
(0.27)\end{array}$ & $\begin{array}{l}-0.35 \\
(0.70)\end{array}$ & $\begin{array}{r}-0.04 \\
(0.22)\end{array}$ & $\begin{array}{l}-0.37 \\
(0.63)\end{array}$ & $\begin{array}{l}-0.41^{*} \\
(0.22)\end{array}$ & $\begin{array}{l}-0.11 \\
(0.64)\end{array}$ & $\begin{array}{r}-0.15 \\
(0.22)\end{array}$ \\
\hline Agg_hs_centered & $\begin{array}{r}-0.28 * * \\
(0.12)\end{array}$ & $\begin{array}{l}-0.16 \\
(0.17)\end{array}$ & $\begin{array}{r}-0.33 * * * \\
(0.10)\end{array}$ & $\begin{array}{r}0.12 \\
(0.17)\end{array}$ & $\begin{array}{l}-0.12 \\
(0.18)\end{array}$ & $\begin{array}{l}-0.06 \\
(0.21)\end{array}$ & $\begin{array}{c}-0.12 \\
(0.16)\end{array}$ & $\begin{array}{r}0.01 \\
(0.19)\end{array}$ \\
\hline Panel_var_time & $\begin{array}{r}0.72 \\
(0.81)\end{array}$ & $\begin{array}{r}-2.15^{* *} \\
(0.95)\end{array}$ & $\begin{array}{r}1.13 \\
(0.99)\end{array}$ & $\begin{array}{r}-1.19 \\
(1.07)\end{array}$ & $\begin{array}{l}1.62 * \\
(0.91)\end{array}$ & $\begin{array}{l}-1.35 \\
(0.89)\end{array}$ & $\begin{array}{r}1.80^{* * * *} \\
(0.68)\end{array}$ & $\begin{array}{r}-1.41 \\
(1.11)\end{array}$ \\
\hline Fix_country_pair & $\begin{array}{l}-1.36^{*} \\
(0.84)\end{array}$ & $\begin{array}{r}0.51 \\
(0.76)\end{array}$ & $\begin{array}{l}-0.62 \\
(0.53)\end{array}$ & $\begin{array}{r}-0.36 \\
(0.38)\end{array}$ & $\begin{array}{l}-1.29 \\
(0.80)\end{array}$ & $\begin{array}{r}0.93 \\
(0.85)\end{array}$ & $\begin{array}{r}-1.91 * * \\
(0.82)\end{array}$ & $\begin{array}{r}-0.52 \\
(0.81)\end{array}$ \\
\hline Zero_treated & $\begin{array}{r}0.45 \\
(0.48)\end{array}$ & $\begin{array}{r}1.01 * * \\
(0.42)\end{array}$ & $\begin{array}{r}0.16 \\
(0.48)\end{array}$ & $\begin{array}{r}1.12 * * * \\
(0.43)\end{array}$ & $\begin{array}{l}-0.18 \\
(0.35)\end{array}$ & $\begin{array}{r}-0.01 \\
(0.41)\end{array}$ & $\begin{array}{r}0.64 \\
(0.45)\end{array}$ & $\begin{array}{r}1.50^{* * *} \\
(0.59)\end{array}$ \\
\hline dev_SPS & $\begin{array}{r}0.10 \\
(0.41)\end{array}$ & $\begin{array}{l}-0.80 \\
(0.49)\end{array}$ & $\begin{array}{r}0.83 * * * \\
(0.34)\end{array}$ & $\begin{array}{r}0.21 \\
(0.62)\end{array}$ & $\begin{array}{r}0.93 * * \\
(0.46)\end{array}$ & $\begin{array}{r}0.14 \\
(0.65)\end{array}$ & $\begin{array}{r}0.81 * * \\
(0.39)\end{array}$ & $\begin{array}{r}-0.42 \\
(0.66)\end{array}$ \\
\hline
\end{tabular}

\begin{tabular}{|c|c|c|c|c|c|c|c|c|c|c|}
\hline \multirow{2}{*}{$\begin{array}{l}\text { Explanatory } \\
\text { Var. }\end{array}$} & \multicolumn{2}{|c|}{ Multinomial Logit } & \multicolumn{2}{|c|}{ Multinomial Logit } & \multicolumn{2}{|c|}{ Multinomial Logit } & \multicolumn{2}{|c|}{ Multinomial Logit } & \multicolumn{2}{|c|}{ Multinomial Logit } \\
\hline & $\log \left(\frac{\mathrm{P}(D=1)}{\mathrm{P}(D=2)}\right)$ & $\left(\frac{\mathrm{P}(D=3)}{\mathrm{P}(D=2)}\right)$ & $\log \left(\frac{\mathrm{P}(D=1)}{\mathrm{P}(D=2)}\right.$ & $g\left(\frac{\mathrm{P}(D=3)}{\mathrm{P}(D=2)}\right)$ & $\log \left(\frac{\mathrm{P}(D=1)}{\mathrm{P}(D=2)}\right)$ & $g\left(\frac{\mathrm{P}(D=3)}{\mathrm{P}(D=2)}\right)$ & $\log \left(\frac{\mathrm{P}(D=1)}{\mathrm{P}(D=2)}\right)$ & $\left(\frac{\mathrm{P}(D=3)}{\mathrm{P}(D=2)}\right)$ & $\log \left(\frac{\mathrm{P}(D=1)}{\mathrm{P}(D=2)}\right)$ & $\mathrm{g}\left(\frac{\mathrm{P}(D=3)}{\mathrm{P}(D=2)}\right)$ \\
\hline Intercept & $\begin{array}{c}1.33 \\
(0.99)\end{array}$ & $\begin{array}{l}-0.04 \\
(0.69)\end{array}$ & $\begin{array}{c}1.84 \\
(1.14)\end{array}$ & $\begin{array}{c}0.48 \\
(0.77)\end{array}$ & $\begin{array}{c}2.20 * * \\
(1.12)\end{array}$ & $\begin{array}{c}0.52 \\
(0.83)\end{array}$ & $\begin{array}{c}2.07 * * \\
(0.88)\end{array}$ & $\begin{array}{c}0.75 \\
(0.80)\end{array}$ & $\begin{array}{c}0.62 \\
(1.03)\end{array}$ & $\begin{array}{c}0.74 \\
(0.55)\end{array}$ \\
\hline$A g$ & $\begin{array}{c}0.34 \\
(0.41)\end{array}$ & $\begin{array}{c}-0.99 * * * \\
(0.24)\end{array}$ & $\begin{array}{c}0.30 \\
(0.42)\end{array}$ & $\begin{array}{c}-1.02 * * * \\
(0.24)\end{array}$ & $\begin{array}{c}0.31 \\
(0.41)\end{array}$ & $\begin{array}{c}-1.03 * * * \\
(0.26)\end{array}$ & $\begin{array}{c}0.25 \\
(0.39)\end{array}$ & $\begin{array}{c}-0.88^{* * *} * \\
(0.23)\end{array}$ & $\begin{array}{c}0.25 \\
(0.45)\end{array}$ & $\begin{array}{c}-1.09 * * * \\
(0.28)\end{array}$ \\
\hline Food & $\begin{array}{c}0.69 \\
(0.46)\end{array}$ & $\begin{array}{c}-0.88^{* *} \\
(0.43)\end{array}$ & $\begin{array}{c}0.68 \\
(0.46)\end{array}$ & $\begin{array}{c}-0.88^{* *} \\
(0.43)\end{array}$ & $\begin{array}{l}0.75^{*} \\
(0.44)\end{array}$ & $\begin{array}{c}-0.90 * * \\
(0.43)\end{array}$ & $\begin{array}{c}0.38 \\
(0.53)\end{array}$ & $\begin{array}{c}-0.63 * * \\
(0.31)\end{array}$ & $\begin{array}{c}0.46 \\
(0.59)\end{array}$ & $\begin{array}{c}-0.92 * * \\
(0.42)\end{array}$ \\
\hline Proxy_dummy & $\begin{array}{c}-2.23 * * * \\
(0.84)\end{array}$ & $\begin{array}{c}-2.08 * * * \\
(0.84)\end{array}$ & $\begin{array}{c}-2.23 * * * \\
(0.80)\end{array}$ & $\begin{array}{c}-2.11 * * * \\
(0.85)\end{array}$ & $\begin{array}{c}-2.48 * * * \\
(0.64)\end{array}$ & $\begin{array}{c}-1.98 * * * \\
(0.55)\end{array}$ & $\begin{array}{c}-1.25^{* *} \\
(0.53)\end{array}$ & $\begin{array}{c}-3.00 * * * \\
(1.03)\end{array}$ & $\begin{array}{c}-1.58 * * \\
(0.66)\end{array}$ & $\begin{array}{c}-2.03 * * \\
(0.91)\end{array}$ \\
\hline Proxy_count & $\begin{array}{c}-2.16^{* *} \\
(0.92)\end{array}$ & $\begin{array}{c}0.87 \\
(0.68)\end{array}$ & $\begin{array}{c}-2.28 * * \\
(0.99)\end{array}$ & $\begin{array}{c}0.73 \\
(0.75)\end{array}$ & $\begin{array}{c}-2.64 * * * \\
(0.69)\end{array}$ & $\begin{array}{c}0.82 \\
(0.74)\end{array}$ & $\begin{array}{l}-1.72^{*} \\
(0.91)\end{array}$ & $\begin{array}{c}0.38 \\
(0.56)\end{array}$ & $\begin{array}{l}-0.40 \\
(0.43)\end{array}$ & $\begin{array}{c}0.58 \\
(0.36)\end{array}$ \\
\hline Proxy_freq & $\begin{array}{c}-1.63 * * \\
(0.78)\end{array}$ & $\begin{array}{c}-2.08 * * * \\
(0.57)\end{array}$ & $\begin{array}{c}-1.51^{* *} \\
(0.68)\end{array}$ & $\begin{array}{c}-2.01 * * * \\
(0.58)\end{array}$ & $\begin{array}{c}-1.51^{* *} \\
(0.70)\end{array}$ & $\begin{array}{c}-1.90 * * * \\
(0.49)\end{array}$ & $\begin{array}{l}-1.47 \\
(0.91)\end{array}$ & $\begin{array}{c}-1.63 * * * \\
(0.56)\end{array}$ & $\begin{array}{l}-0.63 \\
(0.66)\end{array}$ & $\begin{array}{c}-2.08 * * * \\
(0.70)\end{array}$ \\
\hline Sample_centered & $\begin{array}{l}0.02 * \\
(0.01)\end{array}$ & $\begin{array}{c}0.02 * * * \\
(0.01)\end{array}$ & $\begin{array}{l}0.02 * * \\
(0.01)\end{array}$ & $\begin{array}{c}0.03 * * * \\
(0.01)\end{array}$ & $\begin{array}{c}0.02 * * * \\
(0.01)\end{array}$ & $\begin{array}{c}0.03 * * * \\
(0.01)\end{array}$ & $\begin{array}{c}0.02 * * * \\
(0.01)\end{array}$ & $\begin{array}{c}0.03 * * * \\
(0.01)\end{array}$ & $\begin{array}{l}0.02 * * \\
(0.01)\end{array}$ & $\begin{array}{c}0.02 * * \\
(0.01)\end{array}$ \\
\hline SPS_no_mrl & & & $\begin{array}{l}-0.47 \\
(0.40)\end{array}$ & $\begin{array}{c}-0.3 \\
(0.32)\end{array}$ & $\begin{array}{l}-0.54 \\
(0.55)\end{array}$ & $\begin{array}{l}-0.40 \\
(0.37)\end{array}$ & $\begin{array}{l}-0.53 \\
(0.54)\end{array}$ & $\begin{array}{l}-0.42 \\
(0.37)\end{array}$ & $\begin{array}{l}-0.53 \\
(0.46)\end{array}$ & $\begin{array}{l}-0.35 \\
(0.42)\end{array}$ \\
\hline$T B T$ & $\begin{array}{c}0.07 \\
(0.63)\end{array}$ & $\begin{array}{c}0.06 \\
(0.22)\end{array}$ & & & $\begin{array}{l}-0.01 \\
(0.63)\end{array}$ & $\begin{array}{l}-0.08 \\
(0.24)\end{array}$ & $\begin{array}{l}-0.59 \\
(0.77)\end{array}$ & $\begin{array}{l}-0.15 \\
(0.27)\end{array}$ & $\begin{array}{l}-0.59 \\
(0.72)\end{array}$ & $\begin{array}{l}-0.13 \\
(0.28)\end{array}$ \\
\hline Agg_hs_centered & $\begin{array}{l}-0.13 \\
(0.16)\end{array}$ & $\begin{array}{c}0.00 \\
(0.18)\end{array}$ & $\begin{array}{l}-0.10 \\
(0.15)\end{array}$ & $\begin{array}{c}0.03 \\
(0.18)\end{array}$ & & & $\begin{array}{c}-0.26^{* *} \\
(0.12)\end{array}$ & $\begin{array}{c}0.13 \\
(0.19)\end{array}$ & $\begin{array}{c}-0.37 * * * \\
(0.10)\end{array}$ & $\begin{array}{c}0.02 \\
(0.19)\end{array}$ \\
\hline Panel_var_time & $\begin{array}{l}1.72 * * \\
(0.78)\end{array}$ & $\begin{array}{l}-1.19^{*} \\
(0.73)\end{array}$ & $\begin{array}{c}1.71 * * * \\
(0.63)\end{array}$ & $\begin{array}{l}-1.22^{*} \\
(0.74)\end{array}$ & $\begin{array}{c}1.90 * * * \\
(0.71)\end{array}$ & $\begin{array}{l}-1.31 \\
(0.82)\end{array}$ & & & $\begin{array}{c}1.16 \\
(1.16)\end{array}$ & $\begin{array}{l}-1.22 \\
(0.96)\end{array}$ \\
\hline Fix_country_pair & $\begin{array}{c}-1.80^{* * *} \\
(0.80)\end{array}$ & $\begin{array}{c}0.19 \\
(0.61)\end{array}$ & $\begin{array}{c}-1.83 * * * \\
(0.73)\end{array}$ & $\begin{array}{c}0.14 \\
(0.65)\end{array}$ & $\begin{array}{c}-2.08 * * * \\
(0.61)\end{array}$ & $\begin{array}{c}0.21 \\
(0.70)\end{array}$ & $\begin{array}{l}-1.41^{*} \\
(0.86)\end{array}$ & $\begin{array}{l}-0.02 \\
(0.53)\end{array}$ & & \\
\hline Zero_treated & $\begin{array}{c}0.47 \\
(0.44)\end{array}$ & $\begin{array}{c}0.94 * * * \\
(0.34)\end{array}$ & $\begin{array}{c}0.44 \\
(0.39)\end{array}$ & $\begin{array}{c}0.90 \\
(0.36)\end{array}$ & $\begin{array}{c}0.34 \\
(0.46)\end{array}$ & $\begin{array}{c}0.84 * * \\
(0.37)\end{array}$ & $\begin{array}{c}0.64 \\
(0.58)\end{array}$ & $\begin{array}{c}0.53 \\
(0.34)\end{array}$ & $\begin{array}{l}-0.02 \\
(0.37)\end{array}$ & $\begin{array}{c}0.97 * * \\
(0.40)\end{array}$ \\
\hline$d e v \_S P S$ & $\begin{array}{c}0.94 * * \\
(0.46)\end{array}$ & $\begin{array}{c}0.14 \\
(0.55)\end{array}$ & $\begin{array}{l}1.03 * * \\
(0.43)\end{array}$ & $\begin{array}{c}0.20 \\
(0.59)\end{array}$ & $\begin{array}{c}1.12 * * * \\
(0.42)\end{array}$ & $\begin{array}{c}0.12 \\
(0.49)\end{array}$ & $\begin{array}{c}0.56 \\
(0.36)\end{array}$ & $\begin{array}{c}0.69 \\
(0.68)\end{array}$ & $\begin{array}{l}0.81 * * \\
(0.33)\end{array}$ & $\begin{array}{c}0.11 \\
(0.59)\end{array}$ \\
\hline
\end{tabular}




\begin{tabular}{lrrrr} 
Appendix C. Sensitivity of results to variable deletion (one by o \\
\hline Explanatory & \multicolumn{3}{c}{ Multinomial Logit } & \multicolumn{1}{c}{ Multinomial Logit } \\
Var. & $\log \left(\frac{\mathrm{P}(D=1)}{\mathrm{P}(D=2)}\right) \log \left(\frac{\mathrm{P}(D=3)}{\mathrm{P}(D=2)}\right.$ & $\log \left(\frac{\mathrm{P}(D=1)}{\mathrm{P}(D=2)}\right) \log \left(\frac{\mathrm{P}(D=3)}{\mathrm{P}(D=2)}\right)$ \\
& 1.88 & 0.29 & 1.42 & 0.4 \\
Intercept & $(1.23)$ & $(0.93)$ & $(1.06)$ & $(0.89)$ \\
& 0.34 & $-0.84^{* * *}$ & 0.50 & $-0.98^{* * *}$ \\
Ag & $(0.36)$ & $(0.28)$ & $(0.39)$ & $(0.25)$ \\
& $0.73^{*}$ & $-0.68^{* *}$ & $0.86^{* *}$ & $-0.83^{*}$ \\
Food & $(0.40)$ & $(0.38)$ & $(0.42)$ & $(0.45)$ \\
& $-2.27^{* * *}$ & $-2.22^{* *}$ & $-1.31^{* * *}$ & $-1.86^{* * *}$ \\
Proxy_dummy & $(0.92)$ & $(0.95)$ & $(0.47)$ & $(0.42)$ \\
& $-2.12^{* *}$ & 1.11 & $-1.98^{* *}$ & 0.79 \\
Proxy_count & $(1.01)$ & $(0.75)$ & $(0.91)$ & $(0.72)$ \\
& $-1.13^{* *}$ & $-1.07^{* * *}$ & $-1.38^{*}$ & $-1.89^{* * *}$ \\
Proxy_freq & $(0.52)$ & $(0.41)$ & $(0.83)$ & $(0.62)$ \\
& $0.03^{* *}$ & $0.03^{* * *}$ & 0.01 & $0.02^{* *}$ \\
Sample_centered & $(0.01)$ & $(0.01)$ & $(0.01)$ & $(0.01)$ \\
& -0.53 & -0.50 & -0.27 & -0.38 \\
SPS_no_mrl & $(0.47)$ & $(0.37)$ & $(0.52)$ & $(0.38)$ \\
TBT & -0.14 & -0.24 & -0.18 & -0.10 \\
& $(0.62)$ & $(0.22)$ & $(0.70)$ & $(0.23)$ \\
Agg_hs_centered & -0.07 & 0.06 & -0.17 & 0.03 \\
Panel_var_time & $(0.18)$ & $(0.19)$ & $(0.13)$ & $(0.16)$ \\
& $1.75^{* *}$ & -1.04 & 1.19 & -1.28 \\
Fix_country pair & $(0.81)$ & $(0.73)$ & $(0.77)$ & $(0.82)$ \\
Zero_treated & $-1.63^{* *}$ & 0.63 & $-1.63^{* *}$ & 0.25 \\
dev_SPS & $(0.82)$ & $(0.61)$ & $(0.82)$ & $(0.59)$ \\
& & & 0.35 & $0.79^{* *}$ \\
& & & $(0.50)$ & $(0.41)$ \\
& $0.99^{* *}$ & 0.31 & & \\
\hline
\end{tabular}

\section{Appendix D: Influential cluster diagnostics}

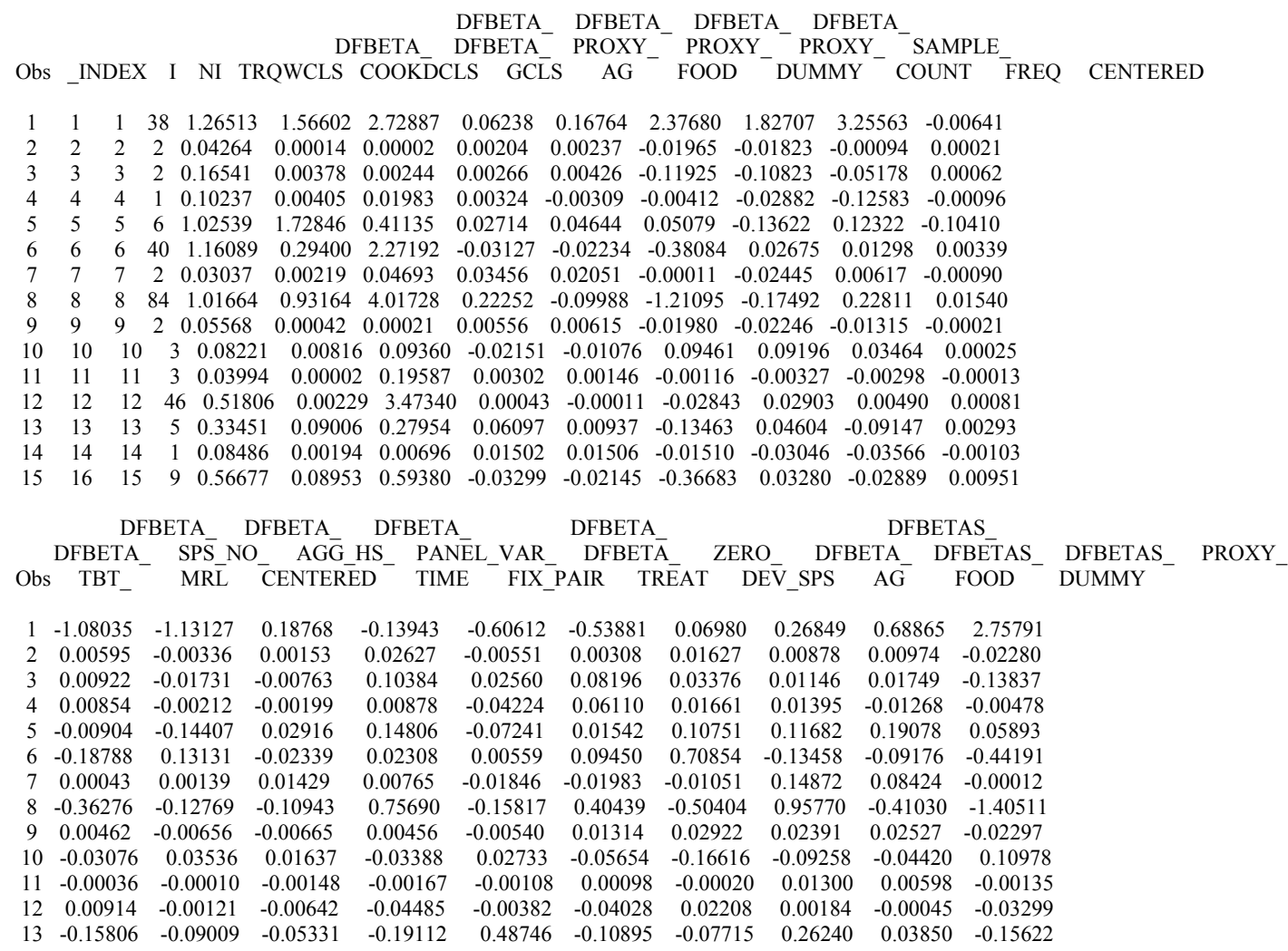


$\begin{array}{lllllllllll}14 & -0.00363 & -0.00211 & -0.02039 & -0.01391 & -0.00457 & 0.01805 & 0.00297 & 0.06465 & 0.06185 & -0.01752\end{array}$

$\begin{array}{lllllllllll}15 & 0.00934 & -0.05911 & 0.05961 & -0.20778 & 0.24915 & 0.05698 & 0.08787 & -0.14198 & -0.08810 & -0.42565\end{array}$

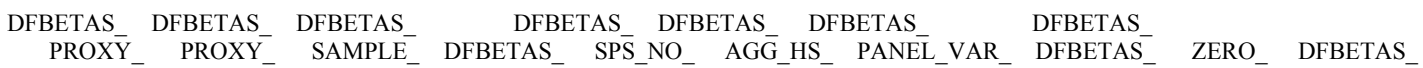

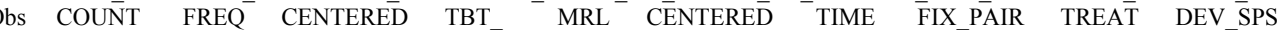

$\begin{array}{ccccccccccc}1 & 2.07424 & 3.62130 & -0.23230 & -2.54296 & -2.78564 & 1.19871 & -0.18881 & -1.17014 & -0.83629 & 0.12200 \\ 2 & -0.02070 & -0.00104 & 0.00751 & 0.01401 & -0.00827 & 0.00980 & 0.03557 & -0.01064 & 0.00479 & 0.02843 \\ 3 & -0.12287 & -0.05760 & 0.02252 & 0.02170 & -0.04263 & -0.04874 & 0.14061 & 0.04942 & 0.12721 & 0.05900 \\ 4 & -0.03272 & -0.13997 & -0.03468 & 0.02011 & -0.00522 & -0.01272 & 0.01189 & -0.08154 & 0.09483 & 0.02902 \\ 5 & -0.15464 & 0.13706 & -3.77411 & -0.02127 & -0.35476 & 0.18626 & 0.20049 & -0.13978 & 0.02393 & 0.18790 \\ 6 & 0.03036 & 0.01444 & 0.12301 & -0.44223 & 0.32334 & -0.14940 & 0.03126 & 0.01079 & 0.14668 & 1.23837 \\ 7 & -0.02775 & 0.00686 & -0.03252 & 0.00100 & 0.00342 & 0.09124 & 0.01036 & -0.03564 & -0.03078 & -0.01838 \\ 8 & -0.19859 & 0.25373 & 0.55825 & -0.85387 & -0.31441 & -0.69889 & 1.02496 & -0.30535 & 0.62766 & -0.88095 \\ 9 & -0.02550 & -0.01463 & -0.00762 & 0.01088 & -0.01616 & -0.04245 & 0.00617 & -0.01042 & 0.02040 & 0.05106 \\ 10 & 0.10440 & 0.03853 & 0.00922 & -0.07241 & 0.08706 & 0.10458 & -0.04588 & 0.05276 & -0.08775 & -0.29041 \\ 11 & -0.00371 & -0.00331 & -0.00489 & -0.00084 & -0.00024 & -0.00942 & -0.00227 & -0.00208 & 0.00152 & -0.00035 \\ 12 & 0.03296 & 0.00546 & 0.02929 & 0.02150 & -0.00299 & -0.04100 & -0.06074 & -0.00738 & -0.06252 & 0.03860 \\ 13 & 0.05227 & -0.10174 & 0.10636 & -0.37205 & -0.22183 & -0.34045 & -0.25880 & 0.94105 & -0.16911 & -0.13484 \\ 14 & -0.03458 & -0.03966 & -0.03748 & -0.00855 & -0.00520 & -0.13023 & -0.01883 & -0.00883 & 0.02801 & 0.00519 \\ 15 & 0.03724 & -0.03214 & 0.34495 & 0.02199 & -0.14555 & 0.38069 & -0.28137 & 0.48098 & 0.08844 & 0.15357\end{array}$

DFBETA_ DFBETA_ DFBETA_ DFBETA

DFBETA DFBETA ${ }^{-}$PROXY ${ }^{-}$PROXY ${ }^{-}$PROXY ${ }^{-}$SAMPLE Obs_INDEX I NI TRQWCLS COOKDCLS GCLS AG FOOD DUMMY COUNT FREQ CENTERED

$\begin{array}{ccccccccccccc}16 & 17 & 16 & 21 & 0.60194 & 0.14801 & 0.73942 & -0.03061 & -0.03032 & 0.02439 & 0.13849 & 0.13159 & 0.00771 \\ 17 & 18 & 17 & 6 & 0.57660 & 0.20906 & 0.17089 & -0.00201 & -0.02267 & -0.44844 & -0.01387 & -0.24454 & 0.00155 \\ 18 & 20 & 18 & 8 & 0.45321 & 0.00175 & 0.38437 & 0.00016 & -0.00025 & 0.00616 & -0.01002 & 0.00437 & 0.00002 \\ 19 & 21 & 19 & 90 & 1.57049 & 0.49289 & 3.09908 & -0.09095 & -0.03326 & -0.60523 & -0.64504 & -1.08274 & 0.00306 \\ 20 & 22 & 20 & 182 & 1.46673 & 0.51056 & 5.46388 & -0.13596 & 0.20653 & 0.25801 & 0.22899 & -0.86096 & 0.00187 \\ 21 & 23 & 21 & 2 & 0.40148 & 0.22611 & 0.24607 & -0.06932 & -0.01907 & 0.61339 & -0.03863 & -0.25924 & -0.01982 \\ 22 & 24 & 22 & 1 & 0.11563 & 0.00448 & 0.01834 & 0.00566 & 0.00031 & 0.00304 & -0.02388 & -0.10397 & -0.00077 \\ 23 & 25 & 23 & 4 & 0.43959 & 0.24532 & 0.25354 & -0.01269 & -0.03666 & 0.33225 & -0.45443 & -0.05981 & -0.01193 \\ 24 & 26 & 24 & 4 & 0.26463 & 0.00301 & 0.14339 & -0.01605 & -0.01404 & -0.02226 & 0.07856 & 0.02900 & 0.00194 \\ 25 & 27 & 25 & 56 & 0.61883 & 0.20499 & 3.92662 & -0.10480 & -0.18842 & 0.18888 & 0.23937 & 0.71814 & -0.00003\end{array}$

DFBETA DFBETA DFBETA DFBETA DFBETAS

DFBETA_ SPS_NO_ AGG_HS_PANEL_VAR_ DFBETA__ ZERO_ DFBETA_ DFBETAS_ DFBETAS_ PROXY Obs TBT_ MRL CENTERED TIME FIX_PAIR TREAT DEV_SPS AG FOOD DUMMY

$\begin{array}{rrrllllllll}16 & -0.17268 & -0.14531 & 0.02930 & 0.10959 & 0.59215 & -0.28690 & 0.07921 & -0.13172 & -0.12455 & 0.02830 \\ 17 & 0.27359 & 0.25912 & 0.07574 & 0.67705 & -0.38290 & 0.17764 & 0.04018 & -0.00867 & -0.09311 & -0.52034 \\ 18 & -0.01749 & 0.03336 & -0.00150 & 0.00840 & -0.01466 & -0.02947 & -0.02856 & 0.00067 & -0.00101 & 0.00714 \\ 19 & 0.96636 & 0.64087 & 0.05015 & 0.18667 & -0.45991 & -0.00801 & 0.11992 & -0.39145 & -0.13664 & -0.70228 \\ 20 & -0.05335 & -0.01106 & -0.07592 & 0.11198 & -0.13811 & -0.45561 & -0.03838 & -0.58515 & 0.84841 & 0.29937 \\ 21 & -0.03035 & -0.14651 & -0.15527 & -0.57159 & 0.11263 & 0.55389 & -0.04331 & -0.29835 & -0.07833 & 0.71174 \\ 22 & 0.01042 & -0.00077 & 0.01365 & 0.02124 & -0.04593 & 0.04435 & 0.01147 & 0.02436 & 0.00129 & 0.00353 \\ 23 & 0.08945 & 0.16300 & 0.09182 & -0.47012 & -0.36150 & 0.37859 & -0.01926 & -0.05461 & -0.15058 & 0.38553 \\ 24 & -0.00795 & -0.01653 & -0.00076 & 0.05449 & 0.04637 & -0.04660 & 0.00183 & -0.06908 & -0.05767 & -0.02583 \\ 25 & 0.08178 & 0.10075 & -0.09083 & -0.10525 & -0.16823 & -0.08655 & 0.00871 & -0.45105 & -0.77403 & 0.21916\end{array}$

DFBETAS_ DFBETAS_ DFBETAS__ DFBETAS_ DFBETAS_ DFBETAS__ DFBETAS

PROXY - PROXY_ SAMPLE_ DFBETAS_ SPS_NO_ AGG_HS_ PANEL_VAR_ DFBETAS _ ZERO_ DFBETAS

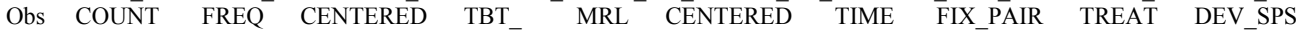

$\begin{array}{rrrrrrrrrrr}16 & 0.15723 & 0.14637 & 0.27966 & -0.40645 & -0.35781 & 0.18716 & 0.14841 & 1.14316 & -0.44529 & 0.13843 \\ 17 & -0.01575 & -0.27201 & 0.05619 & 0.64400 & 0.63806 & 0.48372 & 0.91684 & -0.73921 & 0.27571 & 0.07022 \\ 18 & -0.01138 & 0.00486 & 0.00083 & -0.04116 & 0.08215 & -0.00956 & 0.01138 & -0.02831 & -0.04574 & -0.04991 \\ 19 & -0.73230 & -1.20435 & 0.11094 & 2.27465 & 1.57807 & 0.32027 & 0.25278 & -0.88786 & -0.01242 & 0.20959 \\ 20 & 0.25997 & -0.95766 & 0.06797 & -0.12558 & -0.02724 & -0.48487 & 0.15164 & -0.26662 & -0.70716 & -0.06708 \\ 21 & -0.04386 & -0.28836 & -0.71854 & -0.07144 & -0.36076 & -0.99171 & -0.77402 & 0.21744 & 0.85970 & -0.07569 \\ 22 & -0.02711 & -0.11565 & -0.02810 & 0.02453 & -0.00191 & 0.08718 & 0.02876 & -0.08867 & 0.06884 & 0.02004 \\ 23 & -0.51591 & -0.06653 & -0.43266 & 0.21056 & 0.40138 & 0.58644 & -0.63662 & -0.69788 & 0.58762 & -0.03367 \\ 24 & 0.08919 & 0.03226 & 0.07040 & -0.01872 & -0.04071 & -0.00487 & 0.07379 & 0.08952 & -0.07233 & 0.00319 \\ 25 & 0.27176 & 0.79880 & -0.00101 & 0.19250 & 0.24808 & -0.58013 & -0.14252 & -0.32477 & -0.13433 & 0.01523\end{array}$


Appendix E. Robustness checks. Influential cluster check

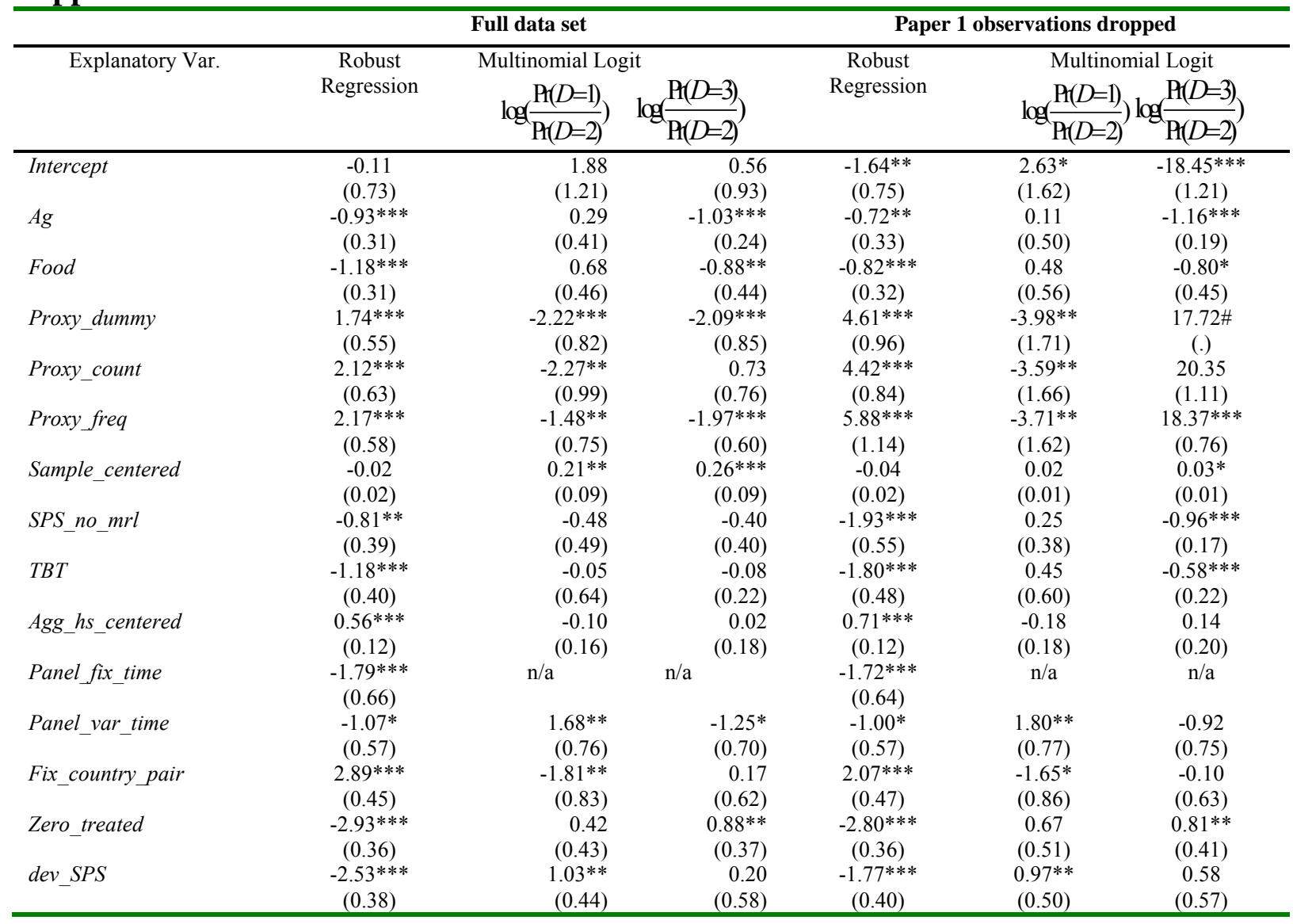

Appendix F: Collinearity diagnostics after dropping paper-1 observations

$\begin{array}{lc}\text { Variable } & \begin{array}{c}\text { Variance } \\ \text { Inflation }\end{array} \\ \text { Intercept } & 0 \\ \text { AG } & 2.50509 \\ \text { FOOD } & 2.09474 \\ \text { PROXY_DU } & 17.90650 \\ \text { PROXY_CO } & 13.08322 \\ \text { PROXY_FR } & 30.19550 \\ \text { sample_centered } & 1.72507 \\ \text { SPS_no_mrl } & 3.48151 \\ \text { TBT } & 4.43546 \\ \text { Agg_hs_centered } & 2.98314 \\ \text { panel_fix_time } & 4.34459 \\ \text { panel_var_time } & 4.14421 \\ \text { fix_pair } & 4.98734 \\ \text { zero_treat } & 3.16858 \\ \text { dev_SPS } & 2.82814\end{array}$


Collinearity Diagnostics

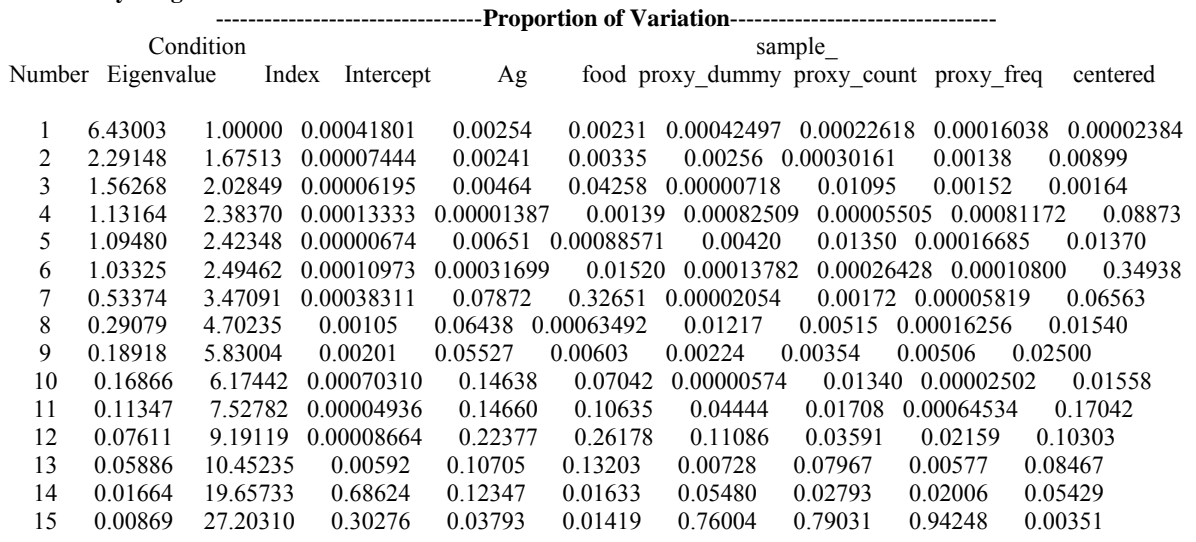

Collinearity Diagnostics

\begin{tabular}{|c|c|c|c|c|c|c|c|c|}
\hline Numbe & \multicolumn{2}{|r|}{$\underset{\text { TBT }}{\operatorname{agg} \text { hs }}$} & $\begin{array}{l}\text { panel_var } \\
\text { centered }\end{array}$ & $\begin{array}{c}\text { panel_fix } \\
\text { time }\end{array}$ & time & fix_pair & zero_treat & dev_SPS \\
\hline 1 & 0.00083842 & 0.00098072 & 0.00023248 & 0.00126 & 0.00107 & 0.00144 & 0.00224 & 0.00207 \\
\hline 2 & 0.00015071 & 0.00282 & 0.00001106 & 0.01764 & 0.01872 & 0.00006463 & 0.00161 & 0.00359 \\
\hline 3 & 0.00004398 & 0.00001173 & 0.00716 & 0.00256 & 0.00676 & 0.00362 & 0.00521 & 0.01579 \\
\hline 4 & 0.00004923 & 0.00003089 & 0.15047 & 0.00873 & 0.00315 & 0.00286 & 0.00255 & 0.02469 \\
\hline 5 & 0.00027011 & 0.00108 & 0.04063 & 0.00812 & 0.00952 & 0.00051777 & 0.00849 & 0.05430 \\
\hline 6 & 0.00015785 & 0.00014323 & 0.05638 & 0.00904 & 0.00209 & 0.00036917 & 0.00820 & 0.00310 \\
\hline 7 & 0.00046510 & $0.00299 \varepsilon$ & $8.326171 \mathrm{E}-7$ & 0.00997 & 0.02195 & 0.00149 & 0.00704 & 0.00025722 \\
\hline 8 & 0.00020810 & 0.04732 & 0.01959 & 0.03187 & 0.00053344 & 0.00008345 & 0.15499 & 0.17123 \\
\hline 9 & 0.05676 & 0.01979 & 0.04746 & 0.10372 & 0.21396 & 0.04419 & 0.05033 & 0.02607 \\
\hline 10 & 0.03064 & 0.02085 & 0.01131 & 0.30420 & 0.29891 & 0.00259 & 0.03243 & 0.06142 \\
\hline 11 & 0.06188 & 0.09443 & 0.00494 & 0.03617 & 0.12637 & .00002564 & 0.00323 & 0.55245 \\
\hline 12 & 0.00000929 & 0.01835 & 0.14883 & 0.32239 & 0.04187 & 0.02462 & 0.53506 & 0.02747 \\
\hline 13 & 0.00004975 & 0.12451 & 0.28033 & 0.12157 & 0.00501 & 0.76144 & 0.07461 & 0.00619 \\
\hline 14 & 0.40015 & 0.36573 & 0.20801 & 0.00561 & 0.24553 & 0.15524 & 0.01016 & 0.00000654 \\
\hline 15 & 0.44832 & 0.30095 & 0.02465 & 0.01715 & 0.00456 & 0.00146 & 0.10387 & 0.05135 \\
\hline
\end{tabular}


Appendix G: Robustness check. Influential cluster checks for papers 5, 8, and 21

\begin{tabular}{|c|c|c|c|c|c|c|c|c|c|c|c|c|}
\hline \multirow{4}{*}{$\begin{array}{l}\text { Explanatory } \\
\text { Var. }\end{array}$} & \multicolumn{3}{|c|}{ Full data set } & \multicolumn{4}{|c|}{ Paper 5 observations dropped } & \multicolumn{3}{|c|}{ Paper 8 observations dropped } & \multicolumn{2}{|c|}{ Paper 21 observations droppec } \\
\hline & \multirow{3}{*}{$\begin{array}{c}\text { Robust } \\
\text { Regression }\end{array}$} & \multicolumn{2}{|c|}{ Multinomial Logit } & \multirow{3}{*}{$\begin{array}{c}\text { Robust } \\
\text { Regression }\end{array}$} & \multicolumn{2}{|c|}{ Multinomial Logit } & \multirow{3}{*}{$\begin{array}{c}\text { Robust } \\
\text { Regression }\end{array}$} & \multicolumn{2}{|c|}{ Multinomial Logit } & \multirow{3}{*}{$\begin{array}{c}\text { Robust } \\
\text { Regression }\end{array}$} & \multicolumn{2}{|c|}{ Multinomial Logit } \\
\hline & & $\operatorname{Pr}(D=1)$ & $\mathrm{P}(D=3)$ & & $\operatorname{Pr}(D=1)$ & $\mathrm{P}(D=3)$ & & $\operatorname{Pr}(D=1)$ & $\mathrm{P}(D=3)$ & & $\operatorname{Pr}(D=1)$ & $\mathrm{P}(D=3)$ \\
\hline & & $\log \left(\frac{1(D-1)}{\mathrm{P}(D=2)}\right)$ & $\log \left(\frac{(\mathrm{P}(D=2)}{2}\right)$ & & $\log \left(\frac{1(D-1)}{\mathrm{P}(D=2)}\right)$ & $\log \left(\frac{(\mathrm{P}(D=2)}{\mathrm{n}}\right)$ & & $\log \left(\frac{1(D-1)}{\mathrm{P}(D=2)}\right)$ & $\log \left(\frac{\mathrm{P}(D=2)}{\mathrm{P}(D)}\right)$ & & $\log \left(\frac{1(D-1)}{\mathrm{P}(D=2)}\right)$ & $\log \left(\frac{\mathrm{P}(D=2)}{\mathrm{P}(D)}\right)$ \\
\hline \multirow[t]{2}{*}{ Intercept } & -0.11 & 1.88 & 0.56 & -0.54 & 1.90 & 0.52 & -0.59 & 1.85 & 0.51 & -0.98 & 2.04 & -1.62 \\
\hline & $(0.73)$ & $(1.21)$ & $(0.93)$ & $(0.80)$ & $(1.20)$ & $(0.92)$ & $(0.82)$ & (1.17) & $(0.82)$ & $(0.86)$ & (1.43) & (1.37) \\
\hline \multirow[t]{2}{*}{$A g$} & $-0.93 * * *$ & 0.29 & $-1.03^{* * *}$ & $-0.88^{* * *}$ & 0.27 & $-0.97 * * *$ & $-0.72 * *$ & -0.07 & $-1.17 * * *$ & $-1.06^{* * * *}$ & 0.39 & $-0.84 * * *$ \\
\hline & $(0.31)$ & $(0.41)$ & $(0.24)$ & $(0.32)$ & $(0.41)$ & $(0.34)$ & $(0.37)$ & $(0.37)$ & $(0.24)$ & $(0.31)$ & $(0.44)$ & $(0.26)$ \\
\hline \multirow[t]{2}{*}{ Food } & $-1.18 * * *$ & 0.68 & $-0.88^{* *}$ & $-1.13^{* * * *}$ & 0.66 & $-0.82^{*}$ & $-1.28^{* * *}$ & 0.76 & $-0.77^{* *}$ & $-1.37^{* * * *}$ & 0.69 & -1.71 \\
\hline & $(0.31)$ & $(0.46)$ & $(0.44)$ & $(0.32)$ & $(0.47)$ & $(0.47)$ & $(0.37)$ & $(0.49)$ & $(0.41)$ & $(0.32)$ & $(0.57)$ & $(0.25)$ \\
\hline \multirow[t]{2}{*}{ Proxy_dummy } & $1.74 * * *$ & $-2.22^{* * *}$ & $-2.09^{* * *}$ & $1.84 * * *$ & $-2.23^{* * *}$ & $-2.09^{* *}$ & $2.45^{* * * *}$ & -1.24 & -1.68 & $1.43^{* * * *}$ & $-1.79 * * *$ & -1.46 \\
\hline & $(0.55)$ & $(0.82)$ & $(0.85)$ & $(0.55)$ & $(0.84)$ & $(1.02)$ & $(0.87)$ & $(1.12)$ & $(1.27)$ & $(0.55)$ & $(0.66)$ & $(0.99)$ \\
\hline \multirow{2}{*}{ Proxy_count } & $2.12^{* * * *}$ & $-2.27 * *$ & 0.73 & $2.11^{* * *}$ & $-2.24 * * *$ & 0.53 & $2.30^{* * *}$ & $-2.22 * * *$ & 0.75 & $1.43^{*}$ & -1.43 & $1.93^{*}$ \\
\hline & $(0.63)$ & $(0.99)$ & $(0.76)$ & $(0.63)$ & $(0.98)$ & $(0.85)$ & $(0.71)$ & $(0.91)$ & $(0.66)$ & $(0.75)$ & $(0.95)$ & $(1.02)$ \\
\hline \multirow{2}{*}{ Proxy_freq } & $2.17 * * *$ & $-1.48^{* *}$ & $-1.97^{* * *}$ & $1.98^{* * *}$ & $-1.47^{* *}$ & $-2.07 * * *$ & $2.30^{* * * *}$ & $-1.71 * *$ & $-2.01 * * *$ & $1.54 * * *$ & -0.93 & $-2.15^{* * *}$ \\
\hline & $(0.58)$ & $(0.75)$ & $(0.60)$ & $(0.58)$ & $(0.75)$ & $(0.59)$ & $(0.65)$ & $(0.77)$ & $(0.57)$ & $(0.60)$ & $(0.71)$ & $(0.73)$ \\
\hline \multirow[t]{2}{*}{ Sample_centered } & -0.02 & $0.21^{* *}$ & $0.26^{* * *}$ & -0.20 & $0.02^{*}$ & 0.01 & -0.03 & $0.02^{*}$ & $0.02 * * *$ & -0.03 & $0.18^{*}$ & $0.24 * * *$ \\
\hline & $(0.02)$ & $(0.09)$ & $(0.09)$ & $(0.13)$ & $(0.01)$ & $(0.03)$ & $(0.03)$ & $(0.01)$ & $(0.01)$ & $(0.02)$ & $(0.10)$ & $(0.09)$ \\
\hline \multirow[t]{2}{*}{ SPS_no_mrl } & $-0.81 * *$ & -0.48 & -0.40 & $-0.69^{*}$ & -0.45 & -0.43 & $-0.71^{*}$ & -0.49 & -0.41 & $-0.97 * *$ & -0.29 & 0.65 \\
\hline & $(0.39)$ & (0.49) & $(0.40)$ & $(0.40)$ & $(0.50)$ & $(0.36)$ & $(0.43)$ & $(0.50)$ & $(0.39)$ & $(0.45)$ & $(0.68)$ & $(0.54)$ \\
\hline \multirow[t]{2}{*}{$T B T$} & $-1.18 * * *$ & -0.05 & -0.08 & $-1.04 * * *$ & -0.08 & -0.05 & $-0.92 * *$ & 0.27 & 0.02 & -0.26 & -0.86 & 0.22 \\
\hline & $(0.40)$ & $(0.64)$ & $(0.22)$ & $(0.41)$ & $(0.66)$ & $(0.24)$ & $(0.48)$ & $(0.66)$ & $(0.23)$ & $(0.55)$ & $(0.69)$ & $(0.62)$ \\
\hline \multirow[t]{2}{*}{ Agg_hs_centered } & $0.56^{* * *}$ & -0.10 & 0.02 & $0.53^{* * *}$ & -0.10 & 0.04 & $0.57 * * *$ & -0.05 & 0.05 & $0.33 * *$ & -0.06 & $-0.29 * *$ \\
\hline & $(0.12)$ & $(0.16)$ & $(0.18)$ & $(0.12)$ & $(0.16)$ & $(0.18)$ & $(0.13)$ & $(0.12)$ & $(0.17)$ & $(0.16)$ & $(0.32)$ & $(0.13)$ \\
\hline \multirow[t]{2}{*}{ Panel_fix_time } & $-1.79 * * *$ & $\mathrm{n} / \mathrm{a}$ & $\mathrm{n} / \mathrm{a}$ & $-1.31^{*}$ & $\mathrm{n} / \mathrm{a}$ & $\mathrm{n} / \mathrm{a}$ & $-1.95^{* * * *}$ & $\mathrm{n} / \mathrm{a}$ & $\mathrm{n} / \mathrm{a}$ & $-0.96^{*}$ & $\mathrm{n} / \mathrm{a}$ & $\mathrm{n} / \mathrm{a}$ \\
\hline & $(0.66)$ & & & $(0.72)$ & & & $(0.75)$ & & & $(0.58)$ & & \\
\hline Panel_var_time & $\begin{array}{l}-1.07 * \\
(0.57)\end{array}$ & $\begin{array}{l}1.68^{* *} \\
(0.76)\end{array}$ & $\begin{array}{l}-1.25^{*} \\
(0.70)\end{array}$ & $\begin{array}{l}-1.15^{* *} \\
(0.57)\end{array}$ & $\begin{array}{l}1.65 * * \\
(0.78)\end{array}$ & $\begin{array}{l}-1.04 \\
(0.87)\end{array}$ & $-1.44 * *$ & 1.17 & $\begin{array}{l}-1.42 * * \\
-(0.58)\end{array}$ & $-1.18^{*}$ & 1.10 & $-1.90 * * *$ \\
\hline \multirow[t]{2}{*}{ Fix_country_pair } & $2.89 * * *$ & $-1.81 * *$ & $\begin{array}{l}(0.0) \\
0.17\end{array}$ & $2.90^{* * *}$ & $\begin{array}{l}(0.18) \\
-1.80^{* * *}\end{array}$ & $\begin{array}{c}(0.8) \\
0.04\end{array}$ & $2.81^{* * *}$ & $\begin{array}{l}(0.93) \\
-1.78^{* *}\end{array}$ & $\begin{array}{l}(0.08) \\
0.20\end{array}$ & $2.95^{* * * *}$ & $\begin{array}{l}(0.17) \\
-1.52^{*}\end{array}$ & $\begin{array}{c}(0.09) \\
0.86\end{array}$ \\
\hline & $(0.45)$ & $(0.83)$ & $(0.62)$ & $(0.45)$ & $(0.82)$ & $(0.72)$ & $(0.51)$ & $(0.76)$ & $(0.52)$ & $(0.47)$ & $(0.88)$ & $(0.76)$ \\
\hline Zero_treated & $-2.93 * * *$ & 0.42 & $0.88 * *$ & $-2.74 * * *$ & 0.40 & $0.99 * *$ & $-2.90 * * *$ & 0.36 & $0.81 * * *$ & $-1.98^{* * * *}$ & -0.10 & $1.48^{* *}$ \\
\hline & $(0.36)$ & $(0.43)$ & $(0.37)$ & $(0.37)$ & $(0.44)$ & $(0.43)$ & $(0.41)$ & $(0.37)$ & $(0.32)$ & $(0.55)$ & $(0.90)$ & $(0.63)$ \\
\hline$d e v \_S P S$ & $-2.53 * * *$ & $1.03^{* *}$ & 0.20 & $-2.58 * * *$ & $1.02^{* *}$ & 0.26 & $-2.30^{* * *}$ & $1.48^{* * *}$ & 0.39 & $-1.85^{* * * *}$ & 0.57 & 0.08 \\
\hline & $(0.38)$ & (0.44) & $(0.58)$ & $(0.38)$ & $(0.43)$ & $(0.62)$ & $(0.49)$ & $(0.40)$ & $(0.45)$ & $(0.49)$ & $(0.42)$ & $(0.93)$ \\
\hline
\end{tabular}




\section{Appendix H. Robustness check on different cutoff points}

\begin{tabular}{|c|c|c|c|c|}
\hline \multirow[b]{2}{*}{ Explanatory Var. } & \multicolumn{2}{|c|}{ Cut off points,+-1.96} & \multicolumn{2}{|c|}{ Cut off points,+-1.64} \\
\hline & $\begin{array}{l}\text { Multinomial Logit } \\
\qquad \log \left(\frac{\mathrm{P}(D=1)}{\mathrm{P}(D=2)}\right)\end{array}$ & $\log \left(\frac{\mathrm{P}(D=3)}{\mathrm{P}(D=2)}\right)$ & $\begin{array}{l}\text { Multinomial } \\
\log \left(\frac{\mathrm{P}(D=3)}{\mathrm{P}(D=2)}\right)\end{array}$ & $\log \left(\frac{\mathrm{P}(D=1)}{\mathrm{P}(D=2)}\right)$ \\
\hline Intercept & $\begin{array}{c}1.88 \\
(1.21)\end{array}$ & $\begin{array}{c}0.56 \\
(0.93)\end{array}$ & $\begin{array}{l}1.93 * \\
(1.13)\end{array}$ & $\begin{array}{c}0.72 \\
(1.04)\end{array}$ \\
\hline$A g$ & $\begin{array}{c}0.29 \\
(0.41)\end{array}$ & $\begin{array}{c}-1.03 * * * \\
(0.24)\end{array}$ & $\begin{array}{c}0.36 \\
(0.41)\end{array}$ & $\begin{array}{c}-1.09 * * \\
(0.29)\end{array}$ \\
\hline Food & $\begin{array}{c}0.68 \\
(0.46)\end{array}$ & $\begin{array}{c}-0.88 * * \\
(0.44)\end{array}$ & $\begin{array}{c}0.75 \\
(0.41)\end{array}$ & $\begin{array}{l}-0.80^{*} \\
(0.46)\end{array}$ \\
\hline Proxy_dummy & $\begin{array}{c}-2.22 * * * \\
(0.82)\end{array}$ & $\begin{array}{c}-2.09 * * * \\
(0.85)\end{array}$ & $\begin{array}{c}-1.88 * * * \\
(0.75)\end{array}$ & $\begin{array}{c}-1.47 * * \\
(0.68)\end{array}$ \\
\hline Proxy_count & $\begin{array}{c}-2.27 * * \\
(0.99)\end{array}$ & $\begin{array}{c}0.73 \\
(0.76)\end{array}$ & $\begin{array}{c}-2.13^{* *} \\
(0.95)\end{array}$ & $\begin{array}{c}0.93 \\
(0.84)\end{array}$ \\
\hline Proxy_freq & $\begin{array}{c}-1.48 * * \\
(0.75)\end{array}$ & $\begin{array}{c}-1.97 * * * \\
(0.60)\end{array}$ & $\begin{array}{l}-1.24^{*} \\
(0.70)\end{array}$ & $\begin{array}{c}-1.72 * * * \\
(0.72)\end{array}$ \\
\hline Sample_centered & $\begin{array}{c}0.02 * * \\
(0.01)\end{array}$ & $\begin{array}{c}0.03 * * * \\
(0.01)\end{array}$ & $\begin{array}{c}0.03 * * * \\
(0.01)\end{array}$ & $\begin{array}{c}0.03 * * * \\
(0.01)\end{array}$ \\
\hline SPS_no_mrl & $\begin{array}{l}-0.48 \\
(0.49)\end{array}$ & $\begin{array}{l}-0.40 \\
(0.40)\end{array}$ & $\begin{array}{l}-0.47 \\
(0.46)\end{array}$ & $\begin{array}{l}-0.42 \\
(0.43)\end{array}$ \\
\hline$T B T$ & $\begin{array}{l}-0.05 \\
(0.64)\end{array}$ & $\begin{array}{l}-0.08 \\
(0.22)\end{array}$ & $\begin{array}{l}-0.05 \\
(0.55)\end{array}$ & $\begin{array}{c}-0.25 \\
(0.24)\end{array}$ \\
\hline Agg_hs_centered & $\begin{array}{l}-0.10 \\
(0.16)\end{array}$ & $\begin{array}{c}0.02 \\
(0.18)\end{array}$ & $\begin{array}{l}-0.06 \\
(0.15)\end{array}$ & $\begin{array}{l}-0.02 \\
(0.19)\end{array}$ \\
\hline Panel fix_time & $\mathrm{n} / \mathrm{a}$ & $\mathrm{n} / \mathrm{a}$ & $\mathrm{n} / \mathrm{a}$ & $\mathrm{n} / \mathrm{a}$ \\
\hline Panel_var_time & $\begin{array}{c}1.68 * * \\
(0.76)\end{array}$ & $\begin{array}{l}-1.25 \\
(0.70)\end{array}$ & $\begin{array}{c}1.34 * * \\
(0.73)\end{array}$ & $\begin{array}{c}-1.29 * * \\
(0.56)\end{array}$ \\
\hline Fix_country_pair & $\begin{array}{c}-1.81 * * \\
(0.83)\end{array}$ & $\begin{array}{c}0.17 \\
(0.62)\end{array}$ & $\begin{array}{c}-1.70 * * \\
(0.80)\end{array}$ & $\begin{array}{c}0.24 \\
(0.66)\end{array}$ \\
\hline Zero_treated & $\begin{array}{c}0.42 \\
(0.43)\end{array}$ & $\begin{array}{c}0.88 * * \\
(0.37)\end{array}$ & $\begin{array}{c}0.31 \\
(0.42)\end{array}$ & $\begin{array}{c}0.93 * * \\
(0.44)\end{array}$ \\
\hline$d e v \_S P S$ & $\begin{array}{l}1.03 * * \\
(0.44)\end{array}$ & $\begin{array}{c}0.20 \\
(0.58)\end{array}$ & $\begin{array}{c}0.92 * * \\
(0.40)\end{array}$ & $\begin{array}{l}-0.24 \\
(0.43)\end{array}$ \\
\hline
\end{tabular}

